\title{
CUESTIONES DE LA JURISDICCIÓN INTERAMERICANA DE DERECHOS HUMANOS*
}

\author{
Sergio GARCÍA RAMÍREZ**
}

RESUMEN: En este artículo se analizan las vertientes jurisdiccionales en las que ejerce atribuciones la Corte Interamericana de Derechos Humanos; consultiva, preventiva y ejecutiva. Asimismo, se da cuenta sobre los criterios sostenidos por este Tribunal con respecto a varios asuntos de su competencia, a la luz de la Convención Americana sobre Derechos Humanos. Finalmente, el artículo incorpora algunas reflexiones sobre el futuro del Sistema Interamericano de Derechos Humanos, considerando la evolución de éste, la situación que guarda en la actualidad y diversos problemas referentes a la consolidación del respeto a los derechos humanos, la universalidad de los derechos y la recepción de éstos en el orden interno.

ABSTRACT: This article analyzes the jurisdictional variants in which the Inter-American Court of Human Rights exercises its attributions: consultative, contentious, preventive and executive. Moreover it mentions the criteria sustained by this Tribunal in respect to the different extremes of its competence as reflected in the American Convention on Human Rights. Finally, the article incorporates some reflections about the future of the Inter-American System of Human Rights, considering its evolution, the actual situation and the divers problems referred to the consolidation of the respect to human rights, the universality and the reception of them in the internal order.

RÉSUMÉ: Dans cet article, sont analyses les versants juridictionnels dans lesquels la Court Interaméricaine des Droits de l'Homme exercice ses attributions: consultative, préventive et exécutive. De la même forme l'article parle des critériums soutenus pour ce Tribunal correspondants aux différents extrêmes de ça compétence comment est reflété dans la Convention Américaine sur Les Droits de l'Homme. Finalement. L'article incorpore quelques reflétions sur le futur du System Interaméricaine des Droit de l'Homme, en faisant un considération de son évolution, la situation de la actualité et divers problèmes référents a la consolidation du respect aux droits de l'homme, l'universalité des droits et sa réception dans le droit intern.

* Este trabajo será utilizado en el prólogo de la valiosa obra de dos destacadas juristas europeas: Les grandes decisions de la Cour Interamericaine des Droits de l'Hom$m e$, de Laurence Burgorgue-Larsen y Amaya Úbeda de Torres. Aquella obra, actualmente en proceso, que a mi juicio posee calidad sobresaliente, examinará las decisiones más relevantes del Tribunal Interamericano y presentará la conexión entre éstas y otros pronunciamientos jurisprudenciales, así como doctrina reciente sobre su materia. Constituirá, por cierto, un primer paso en la difusión de la jurisprudencia interamericana entre los estudiosos francoparlantes. Dedico el trabajo a Laurence Burgorgue-Larsen, profesora de la Universidad de París, en testimonio de amistad y aprecio intelectual.

** Investigador en el Instituto de Investigaciones Jurídicas de la UNAM y presidente de la Corte Interamericana de Derechos Humanos. 


\section{SUMARIO: I. Vertientes jurisdiccionales. II. Temas de la juris- dicción interamericana. III. El futuro del sistema.}

\section{VERTIENTES JURISDICCIONALES}

La misión protectora de la Corte Interamericana se despliega en cuatro vertientes jurisdiccionales. Corrientemente se alude a dos de ellas: consultiva y contenciosa. Me parece pertinente añadir: preventiva y ejecutiva. ${ }^{1}$

La función consultiva ${ }^{2}$ "tiene por finalidad - ha dicho la Cortecoadyuvar al cumplimiento de las obligaciones internacionales de los Estados americanos en lo que concierne a la protección de los derechos humanos, así como al cumplimiento de las funciones que en este ámbito tienen atribuidos los distintos órganos de la OEA". ${ }^{3}$ Esta función no in-

1 Rodolfo E. Piza Escalante, primer presidente de la Corte IDH, considera la posible presencia de otra categoría jurisdiccional, a saber: jurisdicción arbitral (extraordinaria), que se funda en la existencia de una aceptación convencional de la facultad de conocimiento de la Corte, a través de "convención especial"; ésta, prevista en el artículo 62 de la $\mathrm{CADH}$, sugiere la existencia de un acuerdo entre Estados para la solución de una controversia. Cfr. "La jurisdicción contenciosa del Tribunal Interamericano de Derechos Humanos", en varios autores, La Corte Interamericana de Derechos Humanos. Estudios y documentos, San José, Secretaría de la Corte Interamericana de Derechos Humanos-Unión Europea, 1999, pp. 203 y ss.

2 Al respecto, cfr. Ventura Robles, Manuel y Zovatto Garreto, Daniel, La función consultiva de la Corte Interamericana de Derechos Humanos, Madrid, Civitas, 1989; Buergenthal, Thomas, "The advisory practice of the Inter-American Human Rights Court", en varios autores, La Corte Interamericana de Derechos Humanos. Estudios y documentos, Instituto Interamericano de Derechos Humanos, 1985, pp. 27 y ss.; Nikken, Pedro, "La función consultiva de la Corte Interamericana de Derechos Humanos", en varios autores, El Sistema Interamericano de Protección de los Derechos Humanos en el umbral del siglo XXI. Memoria del Seminario. Noviembre de 1999, San José, Corte Interamericana de Derechos Humanos, 2001, t. I, pp. 161 y ss.; Pacheco Gómez, Máximo, "La competencia consultiva de la Corte Interamericana de Derechos Humanos", en id., El Sistema Interamericano de Protección ..., cit. en esta misma nota, pp. 71 y ss.; Pasqualucci, Jo M., The practice and procedure of the Inter-American Court of Human Rights, Cambridge University Press, 2003, pp. 29 y ss.; García Ramírez, Sergio, "Estudio introductorio: La función consultiva de la Corte Interamericana de Derechos Humanos y la OC-18/2003", Corte Interamericana de Derechos Humanos, Opinión Consultiva OC-18/2003, México, Comisión Nacional de los Derechos Humanos, 2004, pp. 9 y ss.

3 "Otros tratados objeto de la función consultiva de la Corte (artículo 64 de la Convención Americana sobre Derechos Humanos”), Opinión Consultiva OC-1/82 del 24 de septiembre de 1982, párrafo 25. 
gresa en cuestiones contenciosas, ${ }^{4}$ pero tampoco se contrae a temas académicos o doctrinales: su materia debe poseer relevancia práctica, acreditada en la realidad. ${ }^{5}$

La tarea consultiva del Tribunal Interamericano tiene mayor alcance - material y subjetivo - que la atribuida a otras instituciones judiciales internacionales. En efecto, puede resolver, a través de opiniones, consultas propuestas por todos los Estados miembros de la Organización de los Estados Americanos - no sólo por los Estados partes en la Convención- y por un amplio número de órganos de la OEA, en el ámbito de sus propias atribuciones. ${ }^{6}$ Las consultas se extienden a todos los tratados internacionales —no únicamente regionales americanos - concernientes a derechos humanos, en amplio sentido. ${ }^{7}$ En lo que corresponde a la Convención Americana, la facultad de opinión que se ha depositado en la Corte comprende cualesquiera cuestiones incluidas en dicho tratado, sin sal-

4 En el Tratado Americano de Soluciones Pacíficas, denominado "Pacto de Bogotá", aprobado en la Novena Conferencia Internacional Americana, en 1948, se acogió una versión de las opinión consultiva que se halla a media vía entre ésta, propiamente, y la decisión arbitral, que tiene efectos vinculantes. En efecto, el artículo LI del instrumento dispone: "Las partes interesadas en la solución de una controversia podrán, de común acuerdo, pedir a la Asamblea General o al Consejo de Seguridad de las Naciones Unidas que soliciten de la Corte Internacional de Justicia opiniones consultivas sobre cualquier cuestión jurídica".

5 La competencia consultiva de la Corte, que implica un "método judicial alterno" para la protección de los derechos humanos, "no debe, en principio, ejercitarse mediante especulaciones puramente académicas, sin una previsible aplicación a situaciones concretas que justifiquen el interés de que se emita una opinión consultiva". "Garantías judiciales en estados de emergencia (artículos 27.2, 25 y 80. Convención Americana sobre Derechos Humanos)", Opinión Consultiva OC-9/87 del 6 de octubre de 1987, párrafo 16.

6 Así, los órganos enumerados en el capítulo X de la Carta de la OEA: Asamblea General, Reunión de Consulta de Ministros de Relaciones Exteriores, Consejos (Consejo Permanente, Consejo Interamericano Económico y Social, Consejo Interamericano para la Educación, la Ciencia y la Cultura), Comité Jurídico Interamericano, Comisión Interamericana de Derechos Humanos, Secretaría General, Conferencias Especializadas y Organismos Especializados (por ejemplo, Organización Panamericana de la Salud, Comisión Interamericana de Mujeres, Instituto Panamericano de Geografía e Historia, Instituto Interamericano de Ciencias Agrícolas, Instituto Indigenista Interamericano e Instituto Interamericano del Niño); artículo 51 de la Carta de la OEA.

7 Es decir, puede opinar sobre derechos contenidos en tratados cuyo objeto y fin no son los derechos humanos, pero que incluyen, circunstancialmente, derechos de particulares. Cfr. "El derecho a la información sobre la asistencia consular", Opinión Consultiva OC-16/99 del 1o. de octubre de 1999, párrafos 72 y ss. 
vedad. Por otra parte, es posible que la Corte opine en torno a la conformidad de leyes nacionales - e incluso de proyectos legislativos_ 8 con tratados internacionales sobre derechos humanos. ${ }^{9}$

En los primeros años de actividad jurisdiccional, la Corte se ocupó, sobre todo, en la atención de consultas provenientes de Estados o de órganos de la OEA. De esta suerte integró una valiosa doctrina que sería cimiento, en muchos aspectos, de futuros pronunciamientos adoptados en asuntos contenciosos. Hasta 2006, la Corte ha emitido diecinueve opiniones consultivas. ${ }^{10}$ En ellas ha examinado las propias atribuciones consul-

8 Cfr. "Propuesta de modificación a la Constitución Política de Costa Rica relacionada con la naturalización", Opinión Consultiva OC-4/84 del 19 de enero de 1984, párrafo 18 , y "Compatibilidad de un proyecto de ley con el artículo 8.2.h de la Convención Americana sobre Derechos Humanos", Opinión Consultiva OC-12/91 del 6 de diciembre de 1991, párrafos 19 y ss.

9 Corresponde comparar estas normas de la CADH con las correspondientes a otros tribunales internacionales, señaladamente la Corte Internacional de Justicia y la Corte Europea de Derechos Humanos. El Tribunal europeo puede opinar acerca de "cuestiones jurídicas relativas a la interpretación del Convenio (europeo) y de sus protocolos" (artículo 47.1 del Convenio), pero sus opiniones "no podrán referirse ni a cuestiones que guarden relación con el contenido o la extensión de los derechos y libertades definidos en el título I del Convenio y en sus protocolos, ni a las demás cuestiones de las que el Tribunal o el Comité de Ministros pudieran conocer de resultas de la presentación de un recurso previsto por el Convenio" (artículo 47.2 del Convenio). Evidentemente, la acotación que hace el mencionado artículo 47 extrae de las atribuciones consultivas de la Corte Europea una porción medular del régimen de los derechos humanos. En cuanto a puntos de legitimación, el Estatuto de la CIJ, de 1945, faculta a ésta para atender solicitudes de "cualquier organismo autorizado para ello por la Carta de las Naciones Unidas, o de acuerdo con las disposiciones de la misma" (artículo 65). Esta Carta resuelve que "la Asamblea General o el Consejo de Seguridad podrán solicitar de la Corte Internacional de Justicia que emita una opinión consultiva sobre cualquier cuestión jurídica" (artículo 96.1); añade: "los otros órganos de las Naciones Unidas y los organismos especializados que en cualquier momento sean autorizados para ello por la Asamblea General, podrán igualmente solicitar a la Corte opiniones consultivas sobre cuestiones jurídicas que surjan dentro de la esfera de sus actividades" (artículo 96.2). Conforme al artículo 47.2 del Convenio Europeo, según las reformas incorporadas por el Protocolo 2, "el Tribunal podrá emitir opiniones consultivas, a solicitud del Comité de Ministros" (del Consejo de Europa). Los Estados signatarios del tratado europeo consideraron — se lee en el preámbulo de Protocolo- "que es oportuno conferir al Tribunal la competencia de emitir, en determinadas condiciones, opiniones consultivas".

10 La primera opinión fue la OC-1/82, en torno a "Otros tratados objeto de la función consultiva de la Corte (artículo 64 de la Convención Americana sobre Derechos Humanos)", solicitada por Perú el 28 de abril de 1982 y resuelta el 24 de septiembre del 
tivas, su extensión y significado; diversos derechos y libertades (libertad de expresión, derecho a la vida, por ejemplo); las leyes violatorias de la Convención; las facultades de algunos órganos del Sistema Interamericano y las características de ciertos actos realizados por éstos; las garantías judiciales en situaciones de emergencia; los derechos de detenidos extranjeros, migrantes y niños, etcétera.

La Corte se ha manifestado con cautela acerca del valor de sus opiniones consultivas: carecen de efectos vinculantes para los Estados. Sin embargo, cierta doctrina sostiene otra cosa, ${ }^{11}$ y algún Estado ha adoptado una posición que pudiera anunciar el rumbo del futuro: la opinión obliga al Estado que la requiere. ${ }^{12}$ En todo caso, la cada vez más frecuente recepción de la jurisprudencia de la Corte por parte de los órganos judiciales nacionales confiere a las opiniones creciente eficacia. Es natural que así sea: la Corte es el intérprete de la Convención Americana y ésta - columna vertebral del ordenamiento regional sobre derechos humanos - forma parte de los ordenamientos nacionales.

La característica función de un tribunal es la solución de controversias a través de sentencias. Esta es la misión de la Corte Interamericana, desarrollada en un número de casos cada vez más amplio. Ya señalé que se hallan legitimados para ejercer la acción procesal la Comisión Interamericana - que lo ha hecho, hasta la fecha, en todos los casos sometidos a la Corte - y los Estados que reconocen la competencia contenciosa de

mismo año; la más reciente ha sido la OC-19/2005, a propósito del "Control de legalidad en el ejercicio de las atribuciones de la Comisión Interamericana de Derechos Humanos (artículos 41 y 44 a 51 de la Convención Americana sobre Derechos Humanos)", propuesta por Venezuela el 12 de noviembre de 2003 y emitida el 28 de noviembre de 2005. Trece solicitudes provinieron de los Estados y seis de la Comisión Interamericana.

11 Cfr. Faúndez Ledesma, El Sistema Interamericano de Protección de los Derechos Humanos. Aspectos institucionales y procesales, 3a. ed., San José, Costa Rica, Instituto Interamericano de Derechos Humanos-Autoridad Noruega para el Desarrollo Internacional-Agencia Sueca de Cooperación Internacional para el Desarrollo, 2004, pp. 989 y ss. Alonso Gómez Robledo atribuye a las opiniones de la Corte "force de droit en lo general”. Cfr. Derechos humanos en el Sistema Interamericano, México, Porrúa-UNAM, Instituto de Investigaciones Jurídicas, 2000, p. 46.

12 Así lo ha considerado la Sala Constitucional (Sala IV) de la Corte Suprema de Costa Rica. Acción de inconstitucionalidad núm. 412-S-90, sentencia 13 noviembre de 1985. 
aquélla — que no han utilizado esta facultad, salvo en una hipótesis, finalmente soslayada por el Tribunal-. ${ }^{13}$

Al resolver sobre el envío de litigios al Tribunal Interamericano, la Comisión sigue el criterio de "oportunidad"; 14 la Corte, en cambio, los debe acoger conforme al principio de "legalidad": en otros términos, no puede atraer o declinar el conocimiento. Ha habido ponderación en la remisión de asuntos. Un flujo excesivo de casos causaría problemas severos a la jurisdicción interamericana - cuyo colegio de jueces no se halla permanentemente reunido, pero debe dictar en "pleno" las sentenciascon grave daño para el sistema y sin beneficio alguno para las víctimas actuales o potenciales. La Corte ha logrado incrementar notablemente el número de sentencias emitidas, merced a las normas reglamentarias vigentes - que permiten la concentración del procedimiento- y a las prácticas adoptadas en los últimos años para el conocimiento y el despacho de los asuntos. ${ }^{15}$

La Corte sólo puede conocer de litigios correspondientes a Estados que han aceptado la competencia contenciosa del tribunal, a través de la cláusula facultativa o de admisión prevista en el Pacto de San José. ${ }^{16}$ En algunas oportunidades se ha sugerido establecer la competencia automá-

13 Me refiero al primer Caso sometido a éste: Viviana Gallardo, correspondiente a Costa Rica. El Estado planteó el tema ante la Corte sin que mediase procedimiento y demanda por parte de la Comisión Interamericana. La Corte estimó insalvable la exigencia convencional de trámite ante la Comisión. En consecuencia, decidió no admitir la demanda y turnó el asunto a la Comisión Interamericana. Cfr. Decisión del 13 de noviembre de 1981, párrafos 20 y ss.

14 En los términos del artículo 44 del Reglamento de la Comisión, ésta debe enviar a la Corte los casos debidamente integrados, salvo "por decisión fundada de la mayoría absoluta de los miembros de la Comisión". Para acordar el envío, "la Comisión considerará fundamentalmente la obtención de justicia en el Caso particular, fundada entre otros, en los siguientes elementos: a) La posición del peticionario; b) La naturaleza y gravedad de la violación; c) La necesidad de desarrollar o aclarar la jurisprudencia del sistema; d) El eventual efecto de la decisión en los ordenamientos jurídicos de los Estados miembros; y e. La calidad de la prueba disponible".

15 Tómese en cuenta, a este respecto, que en 2006 la Corte dictó el mayor número de sentencias (23) con respecto a todos los años transcurridos entre 1987 y aquel año, y que tan sólo entre 2004 y 2006 quedaron resueltos, a través de los pronunciamientos correspondientes, 45 casos contenciosos, en tanto que entre 1987 y 2003 fueron resueltos 40 .

16 La admisión explícita de la competencia contenciosa de la Corte se halla prevista en el artículo 62, CADH. 
tica de la Corte para esos efectos, en relación con todos los Estados partes en ese Pacto. ${ }^{17}$ Este punto plantea el problema de los límites al conocimiento de la Corte previstos por Estados que reconocen su competencia, asunto diverso de las reservas a la Convención.

Esa limitación tiene que ver con la competencia temporal y material de la Corte, entre otros temas. Por lo que toca a aquélla, es relevante la reserva establecida por algunos Estados para impedir el conocimiento de hechos cuyo "principio de ejecución" tuvo lugar antes de que el Estado reconociera la competencia contenciosa. Evidentemente, esta cuestión enlaza con el delicado tema de la desaparición forzada. ${ }^{18} \mathrm{Y}$ por lo que respecta a la competencia material, se han suscitado cuestiones, oportunamente resueltas por el Tribunal, cuando se han establecido limitaciones al conocimiento excesivamente amplias y genéricas, que en rigor entrañan bloqueo de la jurisdicción interamericana en forma inconsecuente con el objeto y fin del tratado. ${ }^{19}$

17 Se ha sugerido la vinculación automática de los Estados partes en la Convención a la competencia contenciosa de la Corte, suprimiendo el acto intermedio de reconocimiento de ésta. Cfr. Cançado Trindade, Antônio, "Bases para un proyecto de Protocolo", en varios autores, El Sistema Interamericano de Protección ..., cit., nota 2, t. II, p. 47.

18 En su reconocimiento de competencia, Chile excluye "hechos cuyo principio de ejecución sea posterior al 11 de marzo de 1990"; El Salvador acepta la competencia por "hechos o actos jurídicos posteriores (a la fecha del reconocimiento) o hechos o actos jurídicos cuyo principio de ejecución sean posteriores a la fecha de depósito de esta Declaración de Aceptación"; y Nicaragua acepta la competencia de la Corte IDH por "hechos posteriores (al reconocimiento) o hechos cuyo principio de ejecución sean posteriores a la fecha de depósito de esta declaración".

19 A este respecto, la Corte resolvió la ineficacia de una declaración formulada por Trinidad y Tobago, porque en los amplios términos de esa declaración, el Estado quedaría facultado "para decidir en cada Caso concreto el alcance de su propia aceptación de la competencia contenciosa de la Corte en detrimento del ejercicio de la función contenciosa del Tribunal. Además, (se) concedería al Estado la potestad discrecional para decidir qué asuntos puede conocer la Corte, lo que privaría el ejercicio de la competencia contenciosa del Tribunal de toda eficacia"; y que aceptar los términos de esa declaración "conduciría a una situación en que la Corte tendría como primer parámetro de referencia la Constitución del Estado y sólo subsidiariamente la Convención Americana, situación que acarrearía una fragmentación del orden jurídico internacional de protección de los derechos humanos y haría ilusorios el objeto y fin de la Convención". Caso Hilaire (Trinidad y Tobago), Excepciones preliminares. Sentencia del 1o. de septiembre de 2001, párrafos 92-93. En el mismo sentido, las sentencias de excepciones dictadas, también el 1o. de septiembre de 2001 en los casos Constantine y otros, y Benjamin y otros. 
La ampliación del corpus juris interamericano sobre derechos humanos ha extendido la competencia material de la Corte. Esta deriva, originaria y esencialmente, de la $\mathrm{CADH}$, seguida por el artículo 1o. del Estatuto de 1979: corresponde a aquélla conocer —en única instancia- de todos los casos concernientes a la interpretación y aplicación de la propia CADH (artículo 62). El Tribunal entiende que en el ejercicio de su función contenciosa sólo puede aplicar en forma inmediata y directa los instrumentos que le confieren competencia material - a la cabeza, la propia $\mathrm{CADH}-,{ }^{20}$ pero puede tomar en cuenta otros ordenamientos internacionales - y así lo ha hecho con frecuencia - para interpretar las disposiciones de los preceptos que le atribuyen aquélla, ${ }^{21} \mathrm{o}$ bien, reconocer que determinada violación a otro tratado también constituye infracción bajo la $\mathrm{CADH} .{ }^{22} \mathrm{La}$ Corte ha de atenerse, en todo caso, a una interpretación evolutiva de los tratados internacionales sobre derechos humanos, considerando — como lo ha hecho la Corte Europea - que éstos "son instru-

20 La Corte ha entendido que de la $\mathrm{CADH}$ "se desprende, con toda claridad, que el procedimiento iniciado en casos contenciosos ante la Comisión que culmine en una demanda ante la Corte, debe referirse precisamente a los derechos protegidos por dicha Convención ( $C f r$. artículos 33, 44, 48.1 y 48). Se exceptúan de esta regla, los casos en que otra Convención, ratificada por el Estado, confiere competencia a la Comisión o a la Corte Interamericanas para conocer de violaciones de los derechos protegidos por dicha Convención". Caso Las Palmeras. Excepciones preliminares (Colombia), Sentencia del 4 de febrero de 2000, párrafo 34. Al respecto, cfr. Remotti Carbonell, José Carlos, La Corte Interamericana de Derechos Humanos. Estructura, funcionamiento y jurisprudencia, Barcelona, Instituto Europeo de Derecho, 2003, pp. 99 y ss.

21 Como ejemplo de esta posición — que no excluye la referencia al "contexto jurídico internacional" en el que se inserta el tratado sujeto a aplicación directa por la Corte- ésta ha señalado que la CADH "sólo ha atribuido competencia a la Corte para determinar la compatibilidad de los actos o de las normas de los Estados con la propia Convención, y no con los Convenios de Ginebra de 1949". Caso Las Palmeras. Excepciones preliminares (Colombia). Sentencia del 4 de febrero de 2000, párrafo 33. Cfr., asimismo, inter alia, Caso Masacre Plan de Sánchez (Guatemala). Sentencia del 29 de abril de 2004, párrafo 51, en lo que respecta a las disposiciones internacionales en materia de genocidio.

22 En este último sentido, y por lo que toca al artículo 3o. común de los Convenios de Ginebra de 1949, la Corte reconoció que "carece de competencia para declarar que un Estado es internacionalmente responsable por la violación de tratados internacionales que no le atribuyen dicha competencia", pero advirtió que hay coincidencia entre la disposición de aquella norma y ciertos preceptos en instrumentos que reconocen competencia material a la Corte IDH. Cfr. Caso Bámaca Velásquez (Guatemala). Sentencia de 25 de noviembre de 2000, párrafo 208. 
mentos vivos, cuya interpretación tiene que acompañar la evolución de los tiempos y las condiciones de vida actuales". ${ }^{23}$

En un voto reciente me referí con cierta extensión a la fuente de la competencia del Tribunal Interamericano:

Las potestades de un órgano jurisdiccional derivan, necesariamente, de la norma que lo instituye, organiza y gobierna. Esta vinculación entre norma jurídica, por una parte, y jurisdicción, por la otra - expresión, en el orden jurisdiccional, del principio de legalidad-, constituye una preciosa garantía para los justiciables y un dato natural y necesario del Estado de derecho. Sería inadmisible y extraordinariamente peligroso para las personas que un órgano jurisdiccional pretendiese "construir", a partir de su voluntad, la competencia que le parezca pertinente. Este "voluntarismo creador de jurisdicción" pondría en riesgo el conjunto de los derechos y las libertades de las personas y constituiría una forma de tiranía no menos lesiva que la ejercida por otros órganos del poder público. Es posible que resulte aconsejable, conforme a la evolución de los hechos o del derecho, extender el ámbito jurisdiccional de un órgano de esta naturaleza, a fin de que concurra mejor a la satisfacción de necesidades sociales. Pero esa extensión debe operar a partir de la norma y no apenas de la decisión voluntariosa $-\mathrm{y}$ en esencia arbitraria- del órgano jurisdiccional. ${ }^{24}$

Por supuesto, sería deseable que la atribución de competencia material en asuntos contenciosos se expresara bajo una misma fórmula acogida en los diversos instrumentos que se refieren a aquélla. Sin embargo, no ha sido así. Esto ha llevado a desplegar las facultades de interpretación de la Corte para analizar y resolver esta cuestión.

Queda claro que el Protocolo de San Salvador concede a la Corte poder decisorio en asuntos relativos a asociación sindical y educación, ${ }^{25} \sin$

23 "El derecho de información sobre la asistencia consular". Opinión Consultiva OC-16/99 del 1o. de octubre de 1999, párrafo 114.

24 Voto en el Caso penal Castro Castro. Sentencia del 25 de noviembre de 2006, párrafo 15 .

25 El artículo 19.6 del protocolo dispone que la violación de los artículos 8.a) (derecho de asociación sindical), y 13 (derecho a la educación) "podría dar lugar", mediante la participación de la Comisión Interamericana de Derechos Humanos, y cuando proceda de la Corte Interamericana de Derechos Humanos, a la aplicación del sistema de peticiones individuales regulado por los artículos 44 a 51 y 61 a 69 de la Convención Americana de Derechos Humanos". No resulta afortunado el empleo de la expresión "podría dar lugar", 
perjuicio del que le reconoce la propia $\mathrm{CADH}$, directamente, en asuntos que también corresponden o pueden corresponder a derechos económicos sociales y culturales: ante todo, el concepto mismo de progresividad y cierta suma de facultades o libertades vinculadas a la igualdad, la no discriminación, la familia, los menores de edad, por ejemplo.

La Convención Interamericana para prevenir y sancionar la tortura, ya aplicada por la Corte y vinculada al artículo 5.2, CADH, opta por otra fórmula: "una vez agotado el ordenamiento jurídico interno del respectivo Estado y los recursos que éste prevé, el caso podrá ser sometido a instancias internacionales cuya competencia haya sido aceptada por ese Estado" (artículo 8o.).

La Convención relativa a desaparición forzada adopta un giro diferente: el trámite de las peticiones o comunicaciones sobre desaparición forzada "estará sujeto a los procedimientos establecidos en la Convención Americana sobre Derechos Humanos, y en los Estatutos y Reglamentos de la Comisión y de la Corte Interamericana de Derechos Humanos, incluso las normas relativas a medidas cautelares" (artículo XIII).

En un caso contencioso reciente, el caso Castro Castro, la Corte examinó la potestad de declarar la existencia de violaciones a la Convención de Belém do Pará sobre violencia contra la mujer, que se refiere a la materia que ahora analizamos bajo el epígrafe "Mecanismos internacionales de protección" (artículo 11). Ésta abre la posibilidad de examinar transgresiones a su artículo 7o., por medio del procedimiento que inicia ante la Comisión Interamericana. En el mismo voto al que supra me referí analizo la competencia material de la Corte para aplicar la Convención de Belém, que ha constituido un paso adelante de notable importancia en la protección jurisdiccional americana de los derechos humanos. ${ }^{26}$

como tampoco la restricción del control a los supuestos considerados en aquellos dos preceptos del Protocolo.

26 Al respecto, manifiesto: “a) El Sistema Interamericano de Protección de Derechos Humanos opera a partir de un corpus juris en expansión, que se propone abarcar la más amplia protección de las personas, tanto a través de normas de alcance ordinario y general, como mediante disposiciones cuyo ámbito de validez subjetiva comprende grupos humanos específicos a los que se destinan declaraciones o medidas de tutela indispensables para el goce y ejercicio efectivos de sus derechos y libertades; b) La atribución de facultades a los órganos de protección internacionales - como a cualesquiera instancias decisorias, de las que depende la definición de derechos y obligaciones - no se sustenta en la simple voluntad de los órganos llamados a ejercerlas, sino en un marco normativo 
Como cualquier tribunal, la Corte Interamericana ha de examinar, en primer término, su competencia para conocer del asunto que se le plantea, trátese de opinión consultiva ${ }^{27} \mathrm{o}$ de caso contencioso, medida provisional o materia ejecutiva. Puesto que nos hallamos ante un tribunal de única instancia, a éste corresponde, en definitiva, la compétence de la compétence, es decir, la atribución inapelable de resolver sobre el alcance de sus atribuciones jurisdiccionales. Esta cuestión ha sido examinada por la Corte en algunas controversias relevantes. Se estableció que el Estado no puede apartarse unilateralmente de la jurisdicción de la Corte cuando previamente la admitió sin restricciones, ${ }^{28}$ criterio cuya validez

suficiente que constituye sustento de la función pública, garantía de seguridad para los participantes y límite al arbitrio de las autoridades; c) Para atribuir facultades de conocimiento a los órganos internacionales de control y supervisión, ese corpus juris no se ha valido de una sola fórmula, que ciña todos los supuestos practicables, sino ha utilizado textos diferentes - hasta cinco, por ahora, como supra se observó-, que deben ser analizados a la luz del conjunto en el que se inscriben y del ordenamiento en el que figuran, tomando en cuenta el objeto y fin de aquél y de éste; d) Esa interpretación se realiza dentro de las fronteras que fijan la $\mathrm{CADH}$, como ordenamiento rector del conjunto, y los instrumentos específicos que se pretende aplicar; uno y otros pueden limitar el conocimiento de un órgano a determinados extremos o permitir el amplio análisis de posibles violaciones. Para establecer el panorama completo de esta materia, en supuestos específicos, habría que considerar, en sus casos, las reservas o limitaciones a la competencia que hubiesen formulado los Estados; e) La interpretación debe atender a las previsiones del artículo 29, CADH, acoger el criterio pro personae propio del derecho internacional de los derechos humanos, favorecer la plena eficacia del tratado en atención a su objeto y fin, y contribuir a la afirmación y fortalecimiento del Sistema Interamericano en esta materia" (voto en el Caso penal Castro Castro, cit., nota 24, párrafo 32).

27 Cfr., inter alia, "Otros tratados objeto de la función consultiva de la Corte (artículo 64 de la CADH)", Opinión Consultiva OC-1/82 del 24 de septiembre de 1982, párrafos 18 y ss., y "El efecto de las reservas sobre la entrada en vigencia de la Convención Americana sobre Derechos Humanos", Opinión Consultiva OC-2/82 del 24 de septiembre de 1982, párrafos 11 y ss.

28 Sobre esta importante materia, planteada y examinada en situaciones particularmente complejas, me remito a mi trabajo "Una controversia sobre la competencia de la Corte Interamericana de Derechos Humanos”, en García Ramírez, Sergio, Estudios jurídicos, México, UNAM, Instituto de Investigaciones Jurídicas, 2000, pp. 389 y ss., y La jurisdicción internacional. Derechos humanos y justicia penal internacional, México, Porrúa, 2003, pp. 269 y ss. En ellos me refiero a las resoluciones sobre competencia adoptadas por la Corte Interamericana en dos asuntos: Caso Ivcher Bronstein (Perú), Competencia. Sentencia del 24 de septiembre de 1999, párrafos 32 y ss., y Caso del Tribunal Constitucional (Perú), Competencia. Sentencia del 24 de septiembre de 1999, párrafos 31 y ss. 
finalmente reconoció el mismo Estado que había planteado ese apartamiento. ${ }^{29}$

También ha habido cuestión a propósito de la facultad de la Corte - en la que se nutre su competencia ejecutiva - para supervisar el cumplimiento de las resoluciones que dicta. Esta es inherente a las atribuciones jurisdiccionales e indispensable para cumplir la obligación que aquélla tiene, conforme al artículo 65, CADH, de informar a la Asamblea General de la OEA sobre el cumplimiento de las determinaciones que dicta el órgano judicial interamericano. ${ }^{30}$

En el ámbito contencioso también interesa la posibilidad de alcanzar la terminación anticipada ${ }^{31}-\mathrm{o}$, mejor dicho, solución alternativa— al litigio a través de la autocomposición unilateral o bilateral. ${ }^{32}$ Esta vía alterna existe en el trámite del asunto ante la propia Comisión Interameri-

29 Perú reconoció el ininterrumpido vínculo con la competencia contenciosa de la Corte. Cfr. "Correspondencia sobre los casos relativos al Perú (2001)", en varios autores, El Sistema Interamericano de Protección..., cit., nota 2, t. II, pp. 529 y ss. En torno a esta cuestión, $c f r$. Javier Valle-Riestra, quien asegura que "el retiro inmediato y unilateral del reconocimiento de la competencia contenciosa de la Corte Interamericana de Derechos Humanos (Resolución Legislativa núm. 27152) es imposible e inválido jurídicamente". La jurisdicción supranacional. Defensa de la competencia contenciosa de la CIDH, Lima, 2000, p. 70.

30 Cfr. Caso Loayza Tamayo (Perú), Cumplimiento de sentencia. Resolución de la Corte de 17 de noviembre de 1999, párrafos 6-9 y res. 1., y Caso Castillo Petruzzi (Perú), Cumplimiento de sentencia. Resolución del 17 de noviembre de 1999, párrafos 4-6 y res. 1. Es particularmente importante la resolución de la Corte en el Caso Baena Ricardo y otros (270 trabajadores) (Panamá), Competencia. Sentencia del 16 de enero de 1998, res. 1-2. En este caso, en el que se definió el criterio del Tribunal, la Corte señaló que "es competente para supervisar el cumplimiento de sus resoluciones" y que en el ejercicio de la competencia que le asiste en esta materia "tiene la facultad de solicitar a los Estados responsables la presentación de informes sobre las gestiones realizadas para dar aplicación a las medidas de reparación ordenadas por ella, de evaluar dichos informes, y de emitir instrucciones y resoluciones sobre el cumplimiento de sus sentencias". Caso Baena Ricardo y otros (270 trabajadores) (Panamá), Competencia. Sentencia del 28 de noviembre de 2003, párrafos 59 y 239.

31 El capítulo V del título II del Reglamento, bajo el epígrafe "Terminación anticipada del proceso", se refiere a desistimiento y allanamiento, y el artículo 54, a "solución amistosa".

32 Utilizo la terminología de Niceto Alcalá-Zamora y Castillo. Cfr. id., Proceso, autocomposición y autodefensa (Contribución al estudio de los fines del proceso), 3a. ed., México, UNAM, Instituto de Investigaciones Jurídicas, 1991, pp. 71 y ss. 
cana a través de la llamada "solución amistosa". ${ }^{33}$ Evidentemente, la autocomposición implica, por una parte, la posibilidad de que las partes dispongan de la materia del proceso - lo cual no ocurre cuando se trata de cuestiones que desbordan esa "dispositividad" y corresponden al orden o interés público-; por la otra, se halla sujeta a la decisión de la Corte, que siempre puede ordenar la continuación del proceso. ${ }^{34}$

Me parece importante observar que la Corte Interamericana, atenta a los fines del proceso sobre derechos humanos — que van más allá de la definición de una verdad "formal", pactada, en el caso concreto- suele admitir prueba, desahogada públicamente, acerca de hechos reconocidos por el Estado y dar cuenta de ellos en la sentencia. En tales casos queda de manifiesto el sentido "pedagógico" o "preventivo" del proceso sobre derechos humanos.

Con creciente frecuencia se solicita al Tribunal la adopción de medidas provisionales, ${ }^{35}$ es decir, providencias precautorias destinadas a poner a salvo bienes jurídicos que corren grave riesgo y cuya lesión pudiera resultar irreparable. ${ }^{36}$ Sobre este punto conviene destacar que conforme a

33 El artículo 48.1.f de la CADH indica que la Comisión "se podrá a disposición de las partes interesadas, a fin de llegar a una solución amistosa del asunto fundada en el respeto a los derechos humanos reconocidos en esta Convención".

34 Al respecto, $c f r$. mi examen sobre la composición (sobre todo cuando se manifiesta en "reconocimiento de responsabilidad", "confesión" o "allanamiento"), en los votos razonados que emití con respecto a las sentencias dictadas en los casos: Barrios Altos (Perú). Sentencia del 14 de marzo de 2001, párrafos 3-4), y Myrna Mack Chang (Guatemala). Sentencia del 25 de noviembre de 2003, párrafos 7 y ss.

35 Sobre esta materia, cfr. Rey Cantor, Ernesto, y Rey Anaya, Ángela Margarita, Medidas provisionales y medidas cautelares en el Sistema Interamericano de Derechos Humanos, presentación de Sergio García Ramírez, Bogotá, Temis-Instituto Interamericano de Derechos Humanos-UNAM, Instituto de Investigaciones Jurídicas, 2005. Asimismo, García Ramírez, Sergio, Los derechos humanos y la jurisdicción interamericana, México, UNAM, Instituto de Investigaciones Jurídicas, pp. 129 y ss., e id., "Las medidas provisionales en la jurisdicción interamericana", La jurisdicción interamericana de derechos humanos. Estudios, México, Comisión de Derechos Humanos del Distrito Federal, 2006, pp. 239 y ss.

36 El Reglamento de la Comisión Interamericana de Derechos Humanos establece la facultad de ésta de dictar medidas "precautorias" (calificación que corresponde, técnicamente, a cualesquiera medidas de este carácter preventivo, independientemente de la autoridad que las adopte), y a la Corte la potestad de emitir medidas "provisionales". Asdrúbal Aguiar-Aranguren abarca, bajo el rubro de cautelares, tanto las medidas así denominadas dentro del Sistema Interamericano, que dicta la Comisión, como las provisionales que se hallan atribuidas a la Corte. $C f r$. "Apuntes sobre las medidas cautelares en la 
la $\mathrm{CADH}$, la Corte puede adoptar medidas tanto cuando conoce de un caso previa demanda sometida a su jurisdicción como antes de que ésta se presente, durante la etapa que se tramita ante la Comisión Interamericana. ${ }^{37}$

La Corte ha resuelto que es pertinente adoptar medidas de esa naturaleza con respecto a cualesquiera derechos humanos - no solamente, como alguna vez se supuso, en torno a los bienes de mayor rango: vida, libertad, por ejemplo- ; 38 que las medidas guardan relación con las características del derecho en riesgo, y por lo tanto pueden asumir diverso contenido; ${ }^{39}$ y que es posible beneficiar con ellas a integrantes de grupos de personas no individualizadas, pero identificables, lo cual amplía notablemente el alcance de la protección cautelar de los derechos humanos. ${ }^{40}$

Los primeros casos llevados al conocimiento de la Corte, a través de las correspondientes demandas, se refirieron al quebranto de derechos esenciales con hechos de extrema violencia: privación de la vida, ataques contra la libertad y la integridad personales. Más tarde aparecieron planteamientos de otro carácter, cuya atención caracteriza una segunda etapa

Convención Americana sobre Derechos Humanos", en Nieto Navia, Rafael (ed.), La Corte y el Sistema Interamericano de Derechos Humanos, San José, Corte Interamericana de Derechos Humanos, pp. 19 y ss.

37 En esta hipótesis todavía no existe proceso; se actúa preventivamente, y cabe la posibilidad - observada con frecuencia - de que transcurra mucho tiempo antes de que se presente demanda formal. En tal virtud, cabe hablar de una competencia puramente "preventiva", desvinculada de la competencia contenciosa, en sentido estricto, que supone la existencia de un litigio y el conocimiento de éste por parte del tribunal. Cfr. García Ramírez, Sergio, "Las medidas provisionales en la jurisdicción interamericana", La jurisdicción interamericana..., cit., nota 35, pp. 246 y 247.

38 Así, en el Caso Herrera Ulloa (inicialmente denominado Caso "La Nación", nombre de un diario costarricense), las medidas adoptadas bajo el concepto de gravedad, urgencia y posibilidad de daño irreparable, ordenaron que se suspendiese la publicación periodística del "Por tanto" de una sentencia condenatoria dictada en contra del periodista quejoso, así como la suspensión de una "liga" en la publicación digital del diario entre los artículos impugnados y la parte dispositiva de la sentencia. Cfr. Resolución sobre medidas provisionales, del 7 de septiembre de 2001, cons. 7 y res. 2.

39 A este respecto, el artículo 63.2, $\mathrm{CADH}$, dispone que "la Corte podrá tomar las medidas que considere pertinentes".

40 Cfr. García Ramírez, Sergio, Voto en Comunidad de Paz de San José de Apartadó (Colombia). Medidas provisionales. Resolución del 24 de noviembre de 2000, Temas de la jurisprudencia interamericana sobre derechos humanos. Votos particulares, México, Instituto Tecnológico de Estudios Superiores de Occidente-Universidad Iberoamericana-Universidad de Guanajuato, 2005, p. 357. 
del quehacer de la Corte: situaciones de notable importancia y menor violencia: diversos derechos de primera generación y cuestiones colindantes con los derechos de segunda o francamente integradas en éstos. ${ }^{41}$ La estadística del periodo 1979-2005 muestra tanto el paulatino incremento de litigios sometidos a la consideración de la Corte - muy escasos en los primeros años — 42 como la diversidad de los temas en los que ha trabajado la jurisprudencia, que es posible plantear a través de conjuntos, aunque sin perder de vista que en múltiples ocasiones un sólo asunto trae consigo la violación de diversos preceptos de la CADH.

En un primer conjunto figuran, con más de siete casos, los litigios en que hubo violaciones en materia de garantías judiciales (artículo 8o., $\mathrm{CADH}$ ): 43; protección judicial (artículo 25): 40; integridad personal (artículo 5o.): 34; libertad personal (artículo 7o.): 28, y vida (artículo 4o.): 26. Enseguida aparecen, con dos a siete casos, los procesos en los que se declaró la violación de los siguientes derechos: legalidad y retroactividad (artículo 9o.) y propiedad privada (artículo 21): siete casos bajo cada concepto; pensamiento y expresión (artículo 13) y derechos del niño (artículo 19): seis; personalidad jurídica (artículo 3o.) y asociación (artículo 16): tres; honra y dignidad (artículo 11), circulación y residencia (artículo 22), derechos políticos (artículo 23) y suspensión de garantías (artículo 27): dos; y conciencia y religión (artículo 12), protección a la familia (artículo 17), nacionalidad (artículo 20) e igualdad ante la ley (artículo 24): uno. ${ }^{43}$

41 Se discute la pertinencia de caracterizar los derechos bajo diversas "generaciones". Esta concepción tiene evidente raíz histórica e ilustra sobre el desarrollo y la protección de los derechos humanos. Cfr. Bidart Campos, Germán F., Teoría general de los derechos humanos, México, UNAM, Instituto de Investigaciones Jurídicas, 1989, pp. 195 y ss. Asimismo, cfr. Rey Cantor, Ernesto y Rodríguez Ruiz, María Carolina, Las generaciones de derechos humanos. Libertad-Igualdad-Fraternidad, 2a. ed., Bogotá, Página Maestra Editores, 2003.

42 Cfr. "Estadísticas de la Corte Interamericana de Derechos Humanos", en varios autores, La Corte Interamericana..., cit., nota 1, p. 492. También la Corte Europea tuvo una primera hora de funcionamiento paulatino. Entre 1959 y 1973, dictó 17 sentencias. En febrero de 1998 había emitido 733. Cfr. "Tribute to Rolv Ryssdal, Ground-Breaker Reformer", The European Convention on Human Rights at 50. Human Rights Information Bulletin, Special issue núm. 50, noviembre de 2000, p. 50.

43 Acerca de las violaciones a derechos previstos en la $\mathrm{CADH}$, en la Convención contra la Tortura y en la Convención contra la Desaparición Forzada, cfr. "Estadísticas 


\section{TEMAS DE LA JURISDICCIÓN INTERAMERICANA}

En su jurisprudencia, la Corte ha destacado el contenido de las denominadas "obligaciones generales del Estado", derivadas de la participación de éste en el régimen convencional de los derechos humanos y recogidas en los artículos 1o. y 2o. de la CADH. Uniformemente se considera que la violación a un derecho o libertad entraña vulneración del artículo 1.1, que se refiere a la obligación de respetar los derechos; y que puede implicar, y así ocurre en muchos casos, quebranto del artículo 2o., acerca del deber de adoptar disposiciones de derecho interno para garantizar los derechos y libertades estatuidos en la Convención.

A partir de las primeras sentencias, la Corte entendió que la obligación descrita en el artículo 1.1 abarca dos deberes: de respeto, por una parte; ${ }^{44}$ de garantía, por la otra. ${ }^{45}$ Esto conduce a organizar el aparato del Estado en forma tal que sirva a esos objetivos ${ }^{46} \mathrm{y}$ a perseguir las conduc-

de la Corte Interamericana de Derechos Humanos", en varios autores, La Corte Interamericana..., cit., nota 1, p. 504.

44 Obviamente, estas obligaciones se instalan sobre un deber más amplio, que es fundamento natural de los otros: el deber de reconocimiento, en cuyos términos el Estado ha de reconocer en su orden interno los derechos y libertades que admite en el orden externo. Otra cosa es la vigencia e intangibilidad de derechos no previstos por la CADH, pero reconocidos en el derecho doméstico o en otros tratados; derivados de la forma democrática representativa de gobierno y contemplados en la Declaración Americana y otros actos internacionales de la misma naturaleza, todo esto en virtud del artículo 29, $\mathrm{CADH}$, relativo a normas de interpretación. En cuanto a la obligación de respeto, $c f r$. Caso Velásquez Rodrígues (Honduras). Sentencia del 29 de julio de 1988, párrafo 165.

45 Cfr. Caso Velásquez Rodríguez (Honduras). Sentencia del 29 de julio de 1988, párrafo 166. Cfr., igualmente, Medina Quiroga, Cecilia, La Convención Americana: teoría y jurisprudencia. Vida, integridad personal, libertad personal, debido proceso y recurso judicial, San José, Costa Rica, Universidad de Chile, Facultad de Derecho, Centro de Derechos Humanos, 2003, pp. 11 y ss. La autora añade la obligación que tienen los Estados de "cooperar con los órganos internacionales que los controlan, que deriva, de manera general, de su calidad de partes del tratado respectivo y de la existencia del principio de derecho internacional que obliga a los Estados a cumplir los tratados de buena fe. Esta obligación aparece de manera específica en la Convención Americana". Id., La Convención Americana..., cit., en esta misma nota, p. 26. De la misma autora, cfr. "Las obligaciones de los Estados bajo la Convención Americana sobre Derechos Humanos", en varios autores, La Corte Interamericana..., cit., nota 1, esp. pp. 242 y ss.

46 La obligación de garantía "implica el deber de los Estados parte (en la CADH) de organizar todo el aparato gubernamental y, en general, todas las estructuras a través de las cuales se manifiesta el ejercicio del poder público, de manera tal que sean capaces de 
tas —atribuibles a aquél— ${ }^{47}$ que transgredan los derechos de los individuos. ${ }^{48}$

La jurisprudencia ha obedecido la previsión enfática del artículo 1.1: "Para los efectos de esta Convención, persona es todo ser humano". Empero, ello no significa ignorancia de los derechos que tienen su fuente o hallan su contenido en figuras de carácter comunitario. Tras los derechos individuales se hallan los derechos colectivos, que no pueden ser olvidados. Esta cuestión adquiere especial importancia cuando se trata de comunidades indígenas; la tutela corresponde a los individuos que las integran, pero adquiere eficacia en la medida en que se admite la existencia de derechos colectivos y se provee a su eficacia. ${ }^{49}$

El derecho a la vida, previsto en el artículo 3o., posee un doble aspecto: positivo y negativo. Este rechaza las intervenciones violatorias del poder público y aquél reclama el establecimiento de condiciones de vida digna. En este último sentido se explaya una relevante jurisprudencia. ${ }^{50}$

asegurar jurídicamente el libre y pleno ejercicio de los derechos humanos". Caso Velásquez Rodrígues (Honduras). Sentencia del 29 de julio de 1988, párrafo 166.

47 Sea porque la realicen agentes del Estado, sea porque, siendo obra de terceros, exista, por parte del Estado, "falta de la debida diligencia para prevenir la violación o para tratarla en los términos requeridos por la Convención”. Caso Velásquez Rodríguez (Honduras). Sentencia del 29 de julio de 1988, párrafo 172.

48 En diversas sentencias, la Corte ha considerado que el Estado es responsable por la conducta violatoria en que incurren miembros de ciertos grupos - patrullas, autodefensas, paramilitares - que actúan con la aquiescencia, colaboración o tolerancia de agentes del poder público. Al respecto, $c f r$. por ejemplo Caso Blake (Guatemala). Sentencia del 24 de enero de 1998, párrafos 75-78; Caso de los 19 Comerciantes (Colombia). Sentencia del 5 de julio de 2004, párrafos 124-125 y 134-141; Caso de la Masacre de Mapiripán (Colombia). Sentencia del 15 de septiembre de 2005, párrafos 110-112 y 116-123; Caso de las Masacres de Ituango (Colombia). Sentencia del 1o. de julio de 2006, párrafos 130-137.

49 Cfr. Caso de la Comunidad Mayagna (Sumo) Awas Tingni (Nicaragua). Sentencia del 31 de agosto de 2001, párrafo 148.

50 Así, "el derecho de los niños a la vida no sólo implica el respeto a las prohibiciones sobre la privación de aquélla, contenidas en el artículo 4o. de la Convención Americana, sino también la dotación de condiciones de vida idóneas para alentar el desarrollo de los menores". Caso de los 'Niños de la Calle' (Villagrán Morales y otros) (Guatemala). Sentencia del 19 de noviembre de 1999, párrafo 144. Cfr. mi voto razonado en el Caso Comunidad Indígena Sawhoyamaxa (Paraguay). Sentencia del 28 de febrero de 2006, en el que señalo: "en materia de derecho a la vida — derecho esencial, radical, soporte del conjunto de los derechos y las libertades - la Corte Interamericana ha llevado a cabo un notable desarrollo jurisprudencial... En sentencias notables, la Corte llamó la 


\section{El Estado puede incurrir en responsabilidad internacional por violación del derecho a la vida cuando ha generado - por acción u omisión- con- diciones tales que conducen, en una relación de causa a efecto razonable- mente acreditada, a la pérdida de la vida. ${ }^{51}$}

atención sobre la otra cara del derecho a la vida, que es contemplada desde distinta perspectiva el otro rostro de los deberes del Estado: ya no sólo de abstención, que frena el arbitrio o modera el castigo, sino de acción, que crea condiciones para la existencia digna. En este sentido, el derecho a la vida recupera su condición primordial como oportunidad para la elección del destino y el desarrollo de las potencialidades; va más allá de ser derecho a la subsistencia: lo es al desarrollo, que se instala en condiciones propicias... La Corte Interamericana se ha internado, con decisión, en este rumbo. Ha afirmado la exigencia de proveer condiciones de vida digna. Ha exaltado los deberes positivos del Estado, no sólo las obligaciones negativas. Y con ello ha trazado una nueva frontera de los derechos humanos al amparo de la Convención Americana. Éste ha sido el criterio firmemente sostenido por la Corte en todas y cada una de sus sentencias recientes. Los argumentos en que se funda se hallan en éstas, ampliamente expuestos". El criterio de la Corte - recuerdo en ese voto- se ha manifestado en los casos Niños de la Calle (Villagrán Morales y otros), Hermanos Gómez Paquiyauri, Instituto de Reeducación del Menor y Yakye Axa. Ha reiterado su interpretación progresiva sobre el alcance del derecho a la vida en los términos del artículo 4o. de la Convención Americana sobre Derechos Humanos, ha insistido en los deberes de conducta activa del Estado — no sólo de abstenciónque derivan de ese alcance, ha subrayado la relación ética — no apenas política: de poder y subordinación- que debe existir entre el Estado".

$51 C f r$. Caso Comunidad Indígena Sawhoyamaxa (Paraguay). Sentencia del 29 de marzo de 2006, párrafos 176-178. Para un análisis de la jurisprudencia de la Corte sobre este extremo, véase mi voto razonado correspondiente a esta sentencia. En éste menciono que "la Corte ha considerado unánimemente que existe la prueba necesaria y suficiente para establecer, una vez formada la convicción personal del juzgador, que las circunstancias en que se encontraban las víctimas determinaron la muerte de éstas; que en todos y cada uno de los supuestos mencionados por la sentencia hay elementos suficientemente convincentes - por encima de la duda que un juzgador de buena fe puede enfrentarpara considerar que la salud de las víctimas se quebrantó por la situación que padecían, que ésta fue el producto directo de las condiciones de vida impuestas por los problemas de asentamiento y marginación en que se hallaban, y que finalmente trajeron como consecuencia inequívoca y directa el fallecimiento de aquéllas; que esas circunstancias resultaron particularmente graves en el caso de menores de edad, que estaban $-\mathrm{o}$ debieron estar - bajo una tutela especial, más diligente; que el resultado de muerte es atribuible al Estado, no ya por la acción de sus agentes como ha ocurrido en otros casos, sino por la omisión -igualmente reprobable, porque implica incumplimiento de deberes estrictosen prever ese resultado, perfectamente previsible, y en proveer lo necesario para impedirlo - provisión que se hallaba al alcance del mismo Estado; y que no es razonable desplazar hacia las víctimas la culpa por el resultado, en virtud de que el Estado contaba con los medios, como se ha dicho, para preverlo y evitarlo, y tenía la obligación de hacerlo". En este caso, la Corte "ha resuelto con apoyo en la reflexión sobre los hechos, la aplicación 
El artículo 3o., que destina su primer párrafo a proclamar el respeto a la vida y reprueba la privación arbitraria de ésta, dedica sus cinco párrafos restantes a restringir, acotar y condicionar la pena de muerte. Este énfasis caracteriza igualmente a otros tratados internacionales sobre derechos humanos. La CADH no suprime la pena capital, pero la restringe notoriamente, en espera de que el Protocolo correspondiente, adoptado por un creciente número de Estados, la suprima en el hemisferio. Ya me he referido, supra, a esta cuestión. Con este marco, la jurisprudencia ha ponderado la reducción de hipótesis en que es aplicable la pena capital — los "delitos más graves" —;52 la imposibilidad de restablecerla en supuestos para los que no se hallaba prevista anteriormente; 53 la necesidad de contar con medios para impugnar eficazmente dicha sanción. ${ }^{54}$

El artículo 5o. se concentra en el derecho a la integridad personal, campo en el que han ocurrido numerosas violaciones, extensamente analizadas por la Corte Interamericana. Aquí figura, con especial relevancia, la proscripción - amparada en el jus cogens, según señalé supra - de la tortura y otros tratos crueles, inhumanos y degradantes, ${ }^{55}$ no sólo en vertiente física, sino también psíquica o psicológica. ${ }^{56} \mathrm{El}$ mismo precepto funda desarrollos de la jurisprudencia en torno a la debida separación entre procesados y sentenciados en los establecimientos de detención, ${ }^{57}$ y acerca de los procedimientos especiales destinados a menores de edad que infringen la ley penal: es preciso separarlos de los adultos, llevarlos ante tribunales especializados — que atienden a reglas procesales igual-

del derecho y la ponderación de la prueba, que cada juzgador, individual o colegiado, debe someter al libre examen de su razón y de su conciencia, con el cuidado que demanda la emisión de una sentencia condenatoria".

$52 C f r$. Caso Hilaire, Constantine, Benjamin y otros (Trinidad y Tobago). Sentencia del 21 de junio de 2002, párrafos 102-109.

53 Cfr. Caso Raxcacó Reyes (Guatemala). Sentencia del 15 de septiembre de 2005, párrafos 64-66.

$54 C f r$. Caso Hilaire, Constantine, Benjamin y otros (Trinidad y Tobago). Sentencia del 21 de junio de 2002, párrafos 187-189.

55 Cfr. Caso Maritza Urrutia (Guatemala). Sentencia del 27 de noviembre de 2003, párrafo 92; Caso Caesar (Trinidad y Tobago). Sentencia del 11 de marzo de 2005.

56 Cfr. Caso Cantoral Benavides (Perú). Sentencia del 18 de agosto de 2000, párrafos 100-102.

57 Cfr. Caso Tibi (Ecuador). Sentencia del 7 de septiembre de 2004, párrafo 158. 
mente específicas, dominadas por el interés superior y el desarrollo integral del niño- y brindarles tratamiento. ${ }^{58}$

Últimamente se ha ocupado la Corte en cuestiones vinculadas al trabajo forzoso u obligatorio, con transgresión del artículo 6o., CADH. Esto así, a propósito de la exigencia de que las víctimas de diversas violaciones realicen determinadas actividades. ${ }^{59}$

El derecho a la libertad personal (artículo 7o.) ha exigido un amplio trabajo jurisprudencial. En este orden se explora y reprueba la privación de libertad en dos vertientes inadmisibles: ilegal o arbitraria. ${ }^{60}$ Otras cuestiones concernientes a la libertad conectan este derecho con puntos relativos al debido proceso: así, la jurisprudencia examina el derecho del sujeto a conocer los motivos de la detención, desde el momento mismo en el que ésta se produce; ${ }^{61}$ el control judicial sobre la legalidad de la detención dentro de un plazo razonable, ${ }^{62}$ tema diferente del plazo razonable para la tramitación y conclusión del proceso al que se refiere el artículo 8o.; el acceso al habeas corpus, fuertemente sostenido por la

58 La Corte ha puntualizado que entre los valores inherentes a una sociedad democrática "figura la salvaguarda de los niños, tanto por su condición de seres humanos y la dignidad inherente a éstos, como por la situación especial en que se encuentran. En razón de su inmadurez y vulnerabilidad, requieren protección que garantice el ejercicio de sus derechos dentro de la familia, de la sociedad y con respecto al Estado". "Estas consideraciones se deben proyectar sobre la regulación de los procedimientos judiciales o administrativos en los que se resuelva acerca de los derechos de los niños y, en su caso, de las personas bajo cuya potestad o tutela se hallan aquéllas". "Condición jurídica y derechos humanos del niño". Opinión Consultiva OC-17/02 del 28 de agosto de 2002, párrafos 93 y 94. Cfr., asimismo, Caso del Instituto de Reeeducación del Menor (Paraguay). Sentencia del 2 de septiembre de 2004, párrafos 209-212.

$59 C f r$. Caso de las Masacres de Ituango (Colombia). Sentencia del 1o. de julio de 2006, párrafo 269 .

60 La legalidad implica que "nadie puede verse privado de la libertad personal sino por las causas, casos o circunstancias expresamente tipificadas por la ley (aspecto material), pero, además, con estricta sujeción a los procedimientos objetivamente definidos por la misma (aspecto formal)". En lo que hace a la exclusión de arbitrariedad, "se está en presencia de una condición según la cual nadie puede ser sometido a detención o encarcelamiento por causas y métodos que - aun calificados de legales - puedan reputarse como incompatibles con el respeto a los derechos fundamentales del individuo por ser, entre otras cosas, irrazonables, imprevisibles, o faltos de proporcionalidad". Caso Gangaram Panday (Suriname). Sentencia del 21 de enero de 1994, párrafo 47.

61 Cfr. Caso Tibi (Ecuador). Sentencia del 7 de septiembre de 2004, párrafo 109.

62 Cfr. Caso Tibi (Ecuador). Sentencia del 7 de septiembre de 2004, párrafos 114, y 118 y 119 . 
jurisprudencia interamericana ${ }^{63}$ y vinculado, en determinadas circunstancias, a la tutela de los derechos inclusive en situaciones de emergencia.

Es copiosa la jurisprudencia de la Corte Interamericana en materia de debido proceso, tema recogido bajo el concepto de "Garantías judiciales", denominación del artículo 8o., pero comprendido también en otros preceptos. ${ }^{64}$ Esa jurisprudencia ha establecido, con signo progresista pro homine, las "nuevas fronteras" del debido proceso ${ }^{65}$ y ha extendido las garantías del orden penal, más numerosas que las previstas para otras materias, a los enjuiciamientos sobre temas diferentes. ${ }^{66}$

En el extenso campo del debido proceso — que no podría siquiera describir en este momento - se ha previsto, por la vía jurisprudencial aplicada a la interpretación y aplicación de la $\mathrm{CADH}$, la exigencia de tribunal independiente, imparcial y competente, ${ }^{67}$ concepto que con frecuencia conduce a examinar y restringir el alcance de la jurisdicción militar: limitada por su materia - delitos de función-y por sus destinatarios — militares en servicio activo — ${ }^{68}$ tema que ha revestido gran im-

$63 C f r$. "El hábeas corpus bajo suspensión de garantías (artículos 27.2, 25.1 y 7.6 de la Convención Americana sobre Derechos Humanos)", Opinión Consultiva OC-8/87 del 30 de enero de 1987; Caso Suárez Rosero (Ecuador). Sentencia del 12 de noviembre de 1997, párrafos 59, 63.

64 Cfr. García Ramírez, Sergio, "Panorama del debido proceso (adjetivo) penal en la jurisprudencia de la Corte Interamericana", Anuario de Derecho Constitucional Latinoamericano, Montevideo, Konrad Adenauer Stiftung, año 12, t. II, pp. 1126 y ss.

$65 C f r$. "El derecho a la información sobre la asistencia consular", Opinión Consultiva OC-16/99 del 1o. de octubre de 1999, párrafos 121-124. Asimismo, cfr. mi voto concurrente razonado a esta Opinión Consultiva, en torno a la "nueva frontera": el debido proceso se halla en constante evolución; la OC-16/99 contiene una "admisión expresa de esta evolución, y por ello recoge lo que pudiera denominarse la 'frontera actual' del procedimiento, que ciertamente va más allá de los linderos trazados anteriormente".

66 El "elenco de garantías mínimas establecido en el numeral 2 del artículo 8o. de la Convención se aplica a los órdenes mencionados en el numeral 1 del mismo artículo, o sea, la determinación de derechos y obligaciones de orden 'civil, laboral, fiscal o de cualquier otro carácter'. Esto revela el amplio alcance del debido proceso; el individuo tiene el derecho al debido proceso entendido en los términos de los artículos 8.1 y 8.2 , tanto en materia penal como en todos estos otros órdenes". Caso Baena Ricardo (Panamá). Sentencia del 2 de febrero de 2001, párrafo 125.

67 Cfr. Caso Castillo Petruzzi (Perú). Sentencia del 30 de mayo de 1999, párrafos 129-132.

68 Cfr. Caso Castillo Petruzzi (Perú). Sentencia del 30 de mayo de 1999, párrafo 128; Caso Cesti Hurtado (Perú). Sentencia del 29 de septiembre de 1999, párrafo 151. 
portancia en el contexto judicial latinoamericano. Esto ha llevado, entre otras consecuencias, a reprobar la figura de los "jueces sin rostro". ${ }^{69}$

La presunción de inocencia constituye el cimiento de diversas garantías en el proceso penal. ${ }^{70}$ Aquí se replantea la exigencia de información acerca de los cargos que pesan sobre el inculpado y que constituyen la materia del proceso - asunto diferente de la información, mencionada supra, que se brinda al detenido-, dato esencial para la preparación de la defensa. ${ }^{71}$ También en este marco se inscribe el más amplio acceso a la defensa profesional, ${ }^{72}$ que debiera ser autónoma, suficiente, oportuna y competente, y la posibilidad real y efectiva de allegar pruebas para el descargo. ${ }^{73}$ Debe existir congruencia entre acusación y sentencia; de lo contrario se vulneraría el derecho a la defensa. ${ }^{74}$

La jurisprudencia interamericana se ha referido al plazo razonable para la conclusión del proceso, cuestión que no permite acotaciones temporales inflexibles, sino requiere examen casuístico sobre la racionalidad del plazo, previa determinación del momento en el que inicia el cómputo de éste, que no es necesariamente aquel en el que interviene el tribunal de conocimiento, porque es preciso tomar en cuenta la diversidad de legislaciones nacionales acerca de la investigación de los delitos y la restricción de derechos del sujeto durante esta etapa. ${ }^{75}$

69 Cfr. Caso Castillo Petruzzi (Perú). Sentencia del 30 de mayo de 1999, párrafo 133.

70 "La Corte considera que el derecho a la presunción de inocencia es un elemento esencial para la realización efectiva del derecho a la defensa, y acompaña al acusado durante toda la tramitación del proceso hasta que una sentencia condenatoria que determine su culpabilidad quede firme. Este derecho implica que el acusado no debe demostrar que no ha cometido el delito que se le atribuye, ya que el onus probando corresponde a quien lo acusa". Caso Ricardo Canese (Paraguay). Sentencia del 31 de agosto de 2004, párrafo 153.

71 Cfr. Caso Tibi (Ecuador). Sentencia del 7 de septiembre de 2004, párrafo 187.

72 Cfr. Caso Castillo Petruzzi (Perú). Sentencia del 30 de mayo de 1999, párrafos 139-141.

73 Cfr. Caso Cantoral Benavides (Perú). Sentencia del 18 de agosto de 2000, párrafo 127.

74 Cfr. Caso Fermín Ramírez (Guatemala). Sentencia del 20 de junio de 2005, párrafos 65-68. Examino el tema con detalle en mi voto razonado correspondiente a esta sentencia.

75 Anteriormente, la Corte estimó que el cómputo del plazo iniciaba con la detención del sujeto ( $c f r$., por ejemplo, Caso Tibi (Ecuador). Sentencia del 7 de septiembre de 2004, párrafo 168). En la actualidad sostiene, con mejor fundamento: "El plazo razonable al que se refiere el artículo 8.1 de la Convención, se debe apreciar en relación con la duración total del procedimiento penal que se desarrolla en contra de cierto imputado, hasta que se dicta sentencia definitiva. En materia penal este plazo comienza cuando se presenta el primer acto de procedimiento dirigido en contra de determinada persona como pro- 
En el análisis del debido proceso se plantea el derecho de recurrir del fallo ante juez o tribunal competente, tema de notable importancia en la reforma procesal penal latinoamericana, que frecuentemente opta por el desempeño de la jurisdicción en única instancia y recurso de casación contra la sentencia. ${ }^{76}$ La Corte Interamericana ha requerido el cumplimiento puntual del artículo 8.2.h de la $\mathrm{CADH}$, que implica la revisión integral del fallo, no apenas el control de constitucionalidad o legalidad. ${ }^{77}$ Esto, que pudiera significar la admisión de modalidades en la inmediación procesal, no significa, en modo alguno, que se deba restablecer o preservar la apelación tradicional.

En el campo de las garantías judiciales figura la proscripción de nuevo juicio por los mismos hechos ${ }^{78}$ en perjuicio del inculpado absuelto. Esta norma enlaza con el principio ne bis in idem y con la cosa juzgada en materia penal. Aludiré a este tema cuando me refiera, infra, a las reparaciones conectadas con la persecución penal del violador de derechos. En cuanto a la publicidad del enjuiciamiento, que también constituye una garantía judicial preciada, hay cierto margen para moderar su aplicación cuando se trate de juzgar a menores de edad. ${ }^{79}$

El tema de las garantías judiciales, acogidas en el artículo 8o., se ha vinculado reiteradamente con la denominada "protección judicial", prevista en el artículo 25. Se trata de materias conexas entre sí, pero deslindables. La protección judicial — extensamente examinada por la jurisprudencia de la Corte Interamericana - entra en juego para la tutela de los

bable responsable de cierto delito". Caso López Álvarez (Honduras). Sentencia del 1o. de febrero de 2006, párrafo 129. Me he referido a este asunto en mis votos razonados a las sentencias de la Corte en los casos López Álvarez (Honduras) y Masacres de Ituango (Colombia).

76 Instituto Iberoamericano de Derecho Procesal, "Exposición de motivos", Código procesal penal modelo para Iberoamérica. Historia. Antecedentes. Exposición de motivos y texto del proyecto, Buenos Aires, Hammurabi, 1989, pp. 26 y 27, donde se pondera el tema a la luz de la inmediación judicial. Cfr. García Ramírez, Sergio, Panorama del proceso penal, México, Porrúa, 2004, pp. 149 y ss.

77 Cfr. Caso Herrera Ulloa (Costa Rica). Sentencia del 2 de julio de 2004, párrafos 158-167.

78 El Pacto Internacional de Derechos Civiles y Políticos se refiere al mismo "delito", concepto más restringido que mismos "hechos". Cfr. Caso Loayza Tamayo (Perú). Sentencia del 17 de septiembre de1997, párrafo 66.

79 "Condición jurídica y derechos humanos del niño", Opinión Consultiva C-17/02 del 28 de agosto de 2002, párrafo 134. 
derechos fundamentales; se traduce, pues, en medios de protección con naturaleza de amparo o habeas corpus, por ejemplo. ${ }^{80}$ Evidentemente, debe observarse el debido proceso cuando venga al caso la protección de derechos fundamentales a través del "recurso sencillo y rápido" o "cualquier otro recurso efectivo ante los jueces o tribunales competentes", a los que se refiere el artículo 25.1. ${ }^{81} \mathrm{La}$ Corte ha precisado que las garantías judiciales destinadas a proteger derechos fundamentales no pueden ser suspendidas en estados de emergencia; son garantía de derechos individuales y preservan el orden jurídico mismo. ${ }^{82}$

La jurisprudencia interamericana ha sostenido con firmeza el principio de legalidad en materia penal. Esto reviste diversas proyecciones. Una de ellas es la formulación rigurosa de los tipos penales, cuya excesiva apertura o ambigüedad deliberada - que se ha observado en determinados casos - apareja violación del artículo 9o., CADH. ${ }^{83}$ Otra proyección del principio se halla en la exclusión de elementos que entrañan juicio sobre la persona, más que sobre la conducta, como ocurre cuando se invoca la peligrosidad del infractor, determinante para la calificación del hecho y la aplicación de la pena. ${ }^{84}$ Bajo el principio de legalidad se ha re-

$80 C f r$. "El hábeas corpus bajo suspensión de garantías (artículos 27.2, 25.1 y 7.6 de la Convención Americana sobre Derechos Humanos)", Opinión Consultiva OC-8/87 del 30 de enero de 1987, párrafos 32-36; "Garantías judiciales en estados de emergencia (artículos 27.2, 25 y 8o. de la Convención Americana sobre Derechos Humanos)”, Opinión Consultiva OC-9/87 del 6 de octubre de 1987, párrafos 22-24, 31-33 y 38; Caso Castillo Páez (Perú). Sentencia del 3 de noviembre de 1997, párrafos 82-83; Caso Cesti Hurtado (Perú). Sentencia del 26 de enero de 1999, párrafo 123; Caso del Tribunal Constitucional (Perú). Sentencia del 31 de enero de 2001, párrafo 91; Caso Cinco Pensionistas (Perú). Sentencia del 28 de febrero de 2003, párrafos 126-138.

$81 C f r$. Hilaire, Constantine, Benjamin y otros (Trinidad y Tobago). Sentencia del 21 de junio de 2002, párrafo 148; Caso Herrera Ulloa (Costa Rica). Sentencia del 2 de julio de 2004, párrafo 163 .

$82 C f r$. "El hábeas corpus bajo suspensión de garantías (artículos 27.2, 25.1 y 7.6 de la Convención Americana sobre Derechos Humanos)", Opinión Consultiva OC-8/87 del 30 de enero de 1987, párrafo 42; "Garantías judiciales en estados de emergencia (artículos 27.2, 25 y 8o. de la. Convención Americana sobre Derechos Humanos)”, Opinión Consultiva OC-9/87 del 6 de octubre de 1987, párrafos 33-37.

83 Cfr. Caso Castillo Petruzzi (Perú). Sentencia del 30 de mayo de 1999, párrafo 121.

84 Cfr. Caso Fermín Ramírez (Guatemala). Sentencia del 20 de junio de 2005, párrafos 92-96. Asimismo, $c f r$. mi voto razonado a esta sentencia. 
chazado la punición de conductas que naturalmente debieran quedar impunes, conforme a un título de justificación: así, el acto médico. ${ }^{85}$

Han llegado al conocimiento de la Corte demandas en las que se plantea la libertad de conciencia y religión, tema que, sin embargo, no ha tenido expresiones prácticas relevantes ni soluciones jurisdiccionales que ameriten referencia en este momento. En cambio, la jurisprudencia del tribunal interamericano ha debido ocuparse en forma creciente y variada de asuntos relativos a la libertad de expresión (artículo 13, CADH), ${ }^{86}$ sostenida con firmeza en diversas manifestaciones o vertientes: en el ejercicio del periodismo, ${ }^{87}$ en campañas políticas, ${ }^{88}$ en la función de medios electrónicos de comunicación social, ${ }^{89}$ en el uso de idiomas cultivados por minorías étnicas, ${ }^{90}$ en el libre y amplio acceso a información pública, ${ }^{91}$ etcétera. Reiteradamente se ha mencionado la existencia de dos dimensiones en la libertad de expresión: individual — manifestación del pensamiento - y colectiva — derecho a recibir informaciones e ideas —.92 Se ha condenado la censura previa ${ }^{93}$ y la obstrucción de la libertad de manifestación de las ideas, que puede valerse de diversos medios, inclu-

85 Cfr. Caso de la Cruz Flores (Perú). Sentencia del 18 de noviembre de 2004, párrafo 102 .

86 Cfr. García Ramírez, Sergio y Gonza, Alejandra, "La libertad de expresión en la jurisprudencia de la Corte Interamericana de Derechos Humanos (artículo 13 de la Convención Americana sobre Derechos Humanos)", Revista de Derecho Público, Buenos Aires, Rubinzal-Culzoni, 2006-2, pp. 459 y ss.

87 Cfr. "La Colegiación Obligatoria de Periodistas (artículos 13 y 29 de la Convención Americana sobre Derechos Humanos)", Opinión Consultiva OC-5/85 del 13 de noviembre de 1985, párrafo 71; Caso Herrera Ulloa (Costa Rica). Sentencia del 2 de julio de 2004, párrafos 117-119.

88 Cfr. Caso Ricardo Canese (Paraguay). Sentencia del 31 de agosto de 2004, párrafos 88-94.

89 Cfr. Caso Ivcher Bronstein (Perú). Sentencia del 6 de febrero de 2001, párrafo 163.

90 Cfr. Caso López Álvarez (Honduras). Sentencia del 1o. de febrero de 2006, párrafos 169 y $172-174$.

91 Cfr. Caso Claude Reyes (Chile). Sentencia del 19 de septiembre de 2006, párrafos 86 y 87.

92 Cfr. "La Colegiación Obligatoria de Periodistas (artículos 13 y 29 de la Convención Americana sobre Derechos Humanos)", Opinión Consultiva OC-5/85 del 13 de noviembre de 1985, párrafos 30-33.

93 Cfr. Caso La última tentación de Cristo (Caso Olmedo Bustos y otros) (Chile). Sentencia del 5 de febrero de 2001, párrafos 71 y 88; Caso Palamara Iribarne (Chile). Sentencia del 22 de noviembre de 2005. 
sive monopolios $\mathrm{u}$ oligopolios de particulares. ${ }^{94}$ La Corte ha destacado, con abundancia, la vinculación entre libertad de expresión y democracia, que constituye uno de los temas clásicos en este campo. ${ }^{95}$

La jurisprudencia interamericana ha tutelado la libertad de asociación (artículo 16), sobre todo en materia laboral, ${ }^{96}$ y en algún caso ha observado que los ataques dirigidos a líderes laborales no sólo implican violación a la libertad, la integridad personal o la vida, en su caso, sino también al derecho de asociación, por cuanto intimida a los actuales o posibles asociados y les priva de gestión o conducción. ${ }^{97}$

Las afectaciones en el acceso al registro civil, que repercuten en el ejercicio de diversos derechos - por ejemplo, acceso a la educación-, traen consigo afectaciones del derecho al nombre (artículo 18) ${ }^{98}$ y vulneran el derecho al reconocimiento de la personalidad jurídica (artículo 3o. ${ }^{99}$ y a la nacionalidad (artículo 20). ${ }^{100}$ En la reflexión sobre esta materia, la Corte ha producido importantes consideraciones a propósito del trato que merecen los migrantes y se ha pronunciado en contra de medidas que afecten el derecho de todas las personas a contar con una nacionalidad. ${ }^{101}$

Los derechos del niño, materia del artículo 19 - con detalle en el Protocolo de San Salvador- han sido invocados en diversas decisiones de la Corte Interamericana: opiniones consultivas o sentencias sobre casos contenciosos. ${ }^{102}$ Prevalece el criterio protector de los niños y adolescentes, que obliga a la adopción de medidas especiales en favor de éstos sujetos, lo cual no implica de ninguna manera - lo ha subrayado la pro-

94 Cfr. op. cit., nota 92, párrafos 34 y 54.

95 Cfr. ibidem, párrafo 71.

96 Cfr. Caso Baena Ricardo y otros (270 trabajadores vs. Panamá). Sentencia de 2 de febrero de 2001, párrafos 166 y 171.

97 Idem. Asimismo, cfr. Caso Huilca Tecse (Perú). Sentencia del 3 de marzo de 2005, párrafo 78 .

98 Caso de las Niñas Yean y Bosico (República Dominicana). Sentencia del 8 de septiembre del 2005, párrafos 182-184.

99 Ibidem, párrafos 178 y ss.

100 Caso Ivcher Bronstein (Perú). Sentencia del 6 de febrero de 2001, párrafos 85-96. Igualmente, cfr. Caso de las Niñas..., cit., nota 98, párrafos 139-141.

101 Caso de las Niñas..., cit., nota 98, párrafo 142.

102 El tribunal interamericano considera que "la prevalencia del interés superior del niño debe ser entendido como la necesidad de satisfacción de todos los derechos de los menores, que obliga al Estado e irradia efectos en la interpretación de todos los demás derechos de la Convención cuando el Caso se refiere a menores de edad". Ibidem, párrafo 134. 
pia Corte- que se les prive de derechos y se les excluya de garantías. Con frecuencia se alude a las proyecciones específicas de los derechos generales y a la gravedad mayor de la conducta violatoria cuando ésta afecta a un menor de edad. ${ }^{103}$

Las disposiciones contenidas en el artículo 21, CADH, en materia de tutela de la propiedad, han conducido a explorar los derechos de individuos pertenecientes a comunidades indígenas, que reclaman territorios ancestrales, y a considerar, en consecuencia, que el concepto "uso y goce de bienes" que utiliza ese precepto puede alojar formas diversas de propiedad, conocidas y consagradas en Estados americanos, incluso modalidades diferentes del dominio en sentido clásico o tradicional. ${ }^{104}$ La tutela provista por el artículo 21, CADH, protege también la posesión. ${ }^{105}$

Últimamente se ha ocupado la jurisprudencia en los problemas que genera el desplazamiento de personas, fenómeno bien conocido en situaciones de conflicto interno. Lo ha hecho con aplicación del artículo 22, $\mathrm{CADH},{ }^{106}$ y ha provisto medidas reparatorias que mencionaré infra.

El planteamiento de violaciones que afecten derechos políticos (artículo 23) no ha sido frecuente. En algún caso relevante se demandó la vulneración de aquéllos en agravio de miembros de agrupaciones indígenas, que enfrentaban mecanismos legales de obstrucción o exclusión con respecto a los derechos de candidatos propuestos por esas agrupaciones. La Corte reconoció la existencia de violaciones y dispuso medidas de reparación consecuentes. ${ }^{107}$

La jurisprudencia interamericana ha sido un baluarte de los principios de no discriminación (artículo 1.1) e igualdad ante la ley (artículo

103 Cfr. idem.

104 Cfr. Caso de la Comunidad Mayagna (Sumo) Awas Tingni (Nicaragua). Sentencia del 31 de agosto de 2001, párrafos 145-153.

105 Cfr. Caso Tibi (Ecuador). Sentencia del 7 de septiembre de 2004, párrafo 218.

106 La Corte ha considerado que el caso del desplazamiento forzado en el interior de un Estado puede ser analizado en los términos del artículo 22 del CADH. El desplazamiento trasciende, sin embargo, el marco de dicho precepto e implica un menoscabo de las condiciones de vida digna. Cfr. Caso de las Masacres de Ituango (Colombia). Sentencia del 1o. de julio de 2006, párrafos 207 y 234.

107 Cfr. Caso Yatama (Nicaragua). Sentencia del 23 de junio de 2005, párrafos 218-220. En mi voto razonado sobre este caso me refiero, entre otras cosas, a las diversas categorías de violaciones con las que se han vulnerado derechos de integrantes de comunidades indígenas: eliminación, exclusión y contención. A esta última categoría corresponden las restricciones consideradas en el Caso Yatama. 
24), sostenidos en forma enérgica y constante. La Corte entiende que estos principios derivan "de la unidad de naturaleza del género humano y (son) inseparables de la dignidad esencial de la persona"; 108 figuran en el jus cogens. ${ }^{109}$ No pueden ser menoscabados en atención a políticas públicas de los Estados, cuestión que incide especialmente en materia de trabajadores migrantes indocumentados. ${ }^{110}$ Por supuesto, la exclusión terminante de normas y otras medidas de discriminación o desigualdad reprobable no impide la adopción de normas y medidas de protección específicas, igualación necesaria, corrección de desequilibrios generados por situaciones de desigualdad real, y otras que tengan fines plausibles y busquen dotar de eficacia a los derechos reconocidos a todas las personas o a ciertas categorías de personas que se hallan en situaciones de desventaja. ${ }^{111}$

En la jurisprudencia interamericana se ha iniciado el tratamiento de los derechos económicos, sociales y culturales, hasta ahora en forma limitada. A la materia se refiere el artículo 26, CADH, que obliga a los Estados a adoptar providencias "para lograr progresivamente la plena efectividad" de esos derechos, derivados de las normas aportadas por el Protocolo de Buenos Aires a la Carta de la OEA. La sede normativa de la materia se halla, desde luego, en el ya mencionado Protocolo de San Salvador. La Corte Interamericana ha considerado que los DESC:

108 "Propuesta de modificación a la Constitución Política de Costa Rica relacionada con la naturalización", Opinión Consultiva OC-4/84 del 19 de enero de 1984, párrafo 55.

109 La Corte ha sostenido que "el principio de igualdad ante la ley, igual protección ante la ley y no discriminación, pertenece al jus cogens, puesto que sobre él descansa todo el andamiaje jurídico del orden público nacional e internacional, y es un principio fundamental que permea todo ordenamiento jurídico... (F)orma parte del derecho internacional general. En la actual etapa de la evolución del derecho internacional, el principio fundamental de igualdad y no discriminación ha ingresado en el dominio del jus cogens". "Condición jurídica y derechos de los migrantes indocumentados", Opinión Consultiva OC-18/03 del 17 de septiembre de 2003, párrafo 101.

110 Cfr. "Condición jurídica y derechos de los migrantes indocumentados", Opinión Consultiva OC-18/03 del 17 de septiembre de 2003, párrafos 169-172.

111 Cfr. "Propuesta de modificación a la Constitución Política de Costa Rica relacionada con la naturalización", Opinión Consultiva OC-4/84 del 19 de enero de 1984, párrafos 56-58; "El derecho a la información sobre la asistencia consular", Opinión Consultiva OC 16/99 del 1o. de octubre de 1999, párrafos 119-123; "Condición jurídica y derechos humanos del niño", Opinión Consultiva OC-17/02 del 28 de agosto de 2002, párrafos 46 y 53-55. 
Tienen una dimensión tanto individual como social. Su desarrollo progresivo... se debe medir, en el criterio de este Tribunal, en función de la creciente cobertura de los derechos económicos, sociales y culturales en general, y del derecho a la seguridad social y a a pensión en particular (nota: en el caso sub judice venía a cuentas un tema de pensión: reducción de ésta, en perjuicio de algunos beneficiarios con percepciones pensionarias superiores a la media de los pensionados en el país), sobre el conjunto de la población, teniendo presentes los imperativos de la equidad social, y no en función de las circunstancias de un muy limitado grupo de pensionistas no necesariamente representativos de la situación general prevaleciente. ${ }^{112}$

\section{EL FUTURO DEL SISTEMA}

En diversos estudios sobre el presente y el futuro del Sistema Interamericano de Protección de Derechos Humanos me he referido a los avances que éste ha tenido y a los temas y problemas que debe afrontar y resolver en el porvenir cercano y distante. ${ }^{113}$

Con la mayor frecuencia se insiste en la necesaria universalización - o "regionalización plena", hemisférica- de los derechos humanos, lo que implica la presencia de todos los Estados de "las Américas", como se suele decir, en la Convención Americana. Ya señalé que de los 34 estados que actualmente integran la Organización de los Estados Americanos, veinticuatro han ratificado la $\mathrm{CADH}$ o han adherido a ella, y veintiuno han reconocido la competencia contenciosa de la Corte. En estos habitan quinientos millones de seres humanos. Es mucho, pero no basta. En América viven ochocientos millones de personas a los que debieran alcanzar los derechos reconocidos en la CADH y la jurisdicción establecida por ésta.

La adopción de los pactos internacionales de Naciones Unidas no justifica la ausencia de Estados americanos en el ordenamiento expedido para este hemisferio, ni obsta para la asunción de compromisos en el ám-

112 Caso "Cinco pensionistas" (Perú). Sentencia del 28 de febrero de 2003, párrafo 147. Cfr. mi voto razonado en este caso, reproducido en Temas de la jurisprudencia..., cit., nota 40, pp. 167-169.

113 Cfr. García Ramírez, Sergio, Los derechos humanos y la jurisdicción..., cit., nota 35, pp. 161 y ss., así como id., "El futuro del Sistema Interamericano de Protección de los Derechos Humanos", en id. (coord.), Jurisprudencia de la Corte Interamericana de Derechos, México, UNAM, 2006, vol. I, pp. 1073 y ss. 
bito americano. Se trata de círculos concéntricos y coexistentes. Así se hizo ver desde que se planteó la interrogante, antes de la aprobación de la $\mathrm{CADH}$, sobre la pertinencia de contar con un ordenamiento regional a pesar de que ya se disponía de uno universal. ${ }^{114}$ Los Estados apoyaron ampliamente la emisión del tratado americano. ${ }^{115}$

Subsiste, pues, la necesidad de contar con "derechos para todos y jurisdicciones para todos". Lo hemos reiterado - y seguramente insistiremos en ello- ante las instancias políticas de la OEA. ${ }^{116}$ En el curso de veinte años — 1978 a 1999 — todos los Estados de América Latina adoptaron la Convención Americana. Como indiqué supra, Brasil y México, cuyas poblaciones constituyen más de la mitad del conjunto, reconocieron la competencia contenciosa de la Corte en 1998, casi simultáneamente. En 1999 lo hizo la República Dominicana. ${ }^{117}$ Las resistencias en este ámbito geopolítico derivaron del concepto de soberanía y de la difícil asunción, jurídica y práctica, de obligaciones internacionales. Así las co-

114 A este respecto, $c f r$. las intervenciones de René Cassin en diversos momentos de la Conferencia Especializada Interamericana sobre Derechos Humanos: primera sesión plenaria del 8 de noviembre de 1969, y primera sesión de la Comisión I del 10 de noviembre de 1969, Conferencia Especializada Interamericana sobre Derechos Humanos. San José, Costa Rica, 7-22 de noviembre de 1969. Actas y Documentos. Secretaría General, Organización de los Estados Americanos, Washington, D. C., rep. 1978, pp. 153 y 154, y 432-435.

115 Lo destaca la Corte, para los fines de la tutela de los derechos humanos, en su jurisprudencia consultiva, cuando examina la conciliación entre universalismo y regionalismo como dato relevante para llevar a buen término un instrumento americano, no obstante la existencia de los Pactos de Naciones Unidas. El punto fue expresamente consultado a los Estados por el Consejo de la OEA. Cfr. "Otros tratados objeto de la función consultiva de la Corte (artículo 64 de la Convención Americana sobre Derechos Humanos). Opinión Consultiva OC-1/82 del 24 de septiembre de 1982, párrafo 47.

116 Así, últimamente, en la Asamblea General de la OEA, el 26 de junio de 2006 (Santo Domingo, República Dominicana): "Echamos de menos —reiteré- la presencia de quienes aún no son partes en la Convención Americana o, siéndolo, todavía no han reconocido la competencia contenciosa de la Corte. Con todo, ésta se extiende hoy a 21 Estados, en los que viven 500 millones de seres humanos. La idea de derechos y jurisdicciones para todos - esto es, la verdadera universalidad de los derechos humanos - ganaría un espacio magnífico cuando se consiga esa presencia. Será mucho lo que aporte hacia el interior de los Estados adherentes, y mucho más lo que signifique para el conjunto. Se halla pendiente, pues, el ingreso al sistema de la Convención de países en los que habitan 350 millones de personas. Esta es la dimensión de la tarea pendiente".

117 República Dominicana reconoció la competencia contenciosa de la Corte el 25 de marzo de 1999. El 4 de junio de 2000 lo hizo Barbados. 
sas, la Convención y la jurisdicción de la Corte Interamericana se hallan asociadas al área latinoamericana del hemisferio. Esto genera un "espacio judicial" en materia de derechos humanos, con signo diferente del que existe en el ámbito europeo.

Es distinta la situación que prevalece en el Caribe, que también forma parte, por supuesto, de "las Américas" y tiene presencia, numerosa e importante, en la Organización de los Estados Americanos. Al respecto, conviene distinguir entre los países de tradición jurídica inglesa, angloparlantes, y los de tradición continental europea localizados físicamente en el área caribeña: Haití y República Dominicana. A su vez, Suriname, antigua Antilla Holandesa - que es parte en la Convención y ha reconocido la competencia de la Corte_-, ${ }^{118}$ ofrece características propias de los países caribeños con tradición jurídica anglosajona, varios son partes en la CADH —-Barbados, Dominica, Grenada y Jamaica—, y sólo Barbados — ${ }^{119}$ ha aceptado la competencia contenciosa de la Corte Interamericana. ${ }^{120}$

Es preciso entender los factores de esta distancia entre el sistema tutelar de los derechos humanos y el universo caribeño, del que ha habido representantes tanto en la Comisión como en la Corte interamericanas. ${ }^{121}$ Existen diferencias de alguna entidad entre los regímenes jurídicos de genealogía inglesa y española o portuguesa, ${ }^{122}$ que se proyectan sobre

118 La Corte ha conocido y resuelto tres litigios concernientes a Suriname: Caso Aloeboetoe y otros (sentencia sobre el fondo, de 4 de diciembre de 1991, y sentencia sobre reparaciones, de 10 de septiembre de 1993), Caso Gangaram Panday (sentencia acerca de excepciones preliminares, de 4 de diciembre de 1991, y sentencia en cuanto al fondo, de 21 de enero de 1994) y Caso de la Comunidad Moiwana (sentencia de 15 de junio de 2005, y sentencia de interpretación, de 8 de febrero de 2006).

119 Barbados aceptó la competencia contenciosa de la Corte el 4 de junio de 2000. Con respecto a este país — hasta agosto de 2006 — sólo una vez se ha dictado medidas provisionales.

120 Como antes dije, el problema de mayor gravedad en la relación entre un país del área y el Sistema Interamericano de Protección de los Derechos Humanos se presentó cuando Trinidad y Tobago denunció la Convención Americana, tras algunas tensiones con los órganos de protección internacional.

121 Por lo que toca a la Corte, figuran los jueces Oliver Jackman (Barbados), Huntley Eugene Munroe (Jamaica) y Margarette May Macaulay (Jamaica), esta última electa por la Asamblea General en 2006 para el periodo de seis años que inicia en 2007.

122 Cfr. Jackman, Oliver, "Living Memory of the Inter-American System of Human Rights", en varios autores, La Corte Interamericana..., cit., nota 1, pp. 151 y ss. 
este asunto. Un tema sensible es la pena de muerte. ${ }^{123}$ Ha sido en torno a ésta - por cuestiones procesales, más que sustantivas- que surgieron las principales controversias. Es notorio que la Convención Americana milita a favor del abolicionismo, aunque no lo acoja enteramente; y también lo es la opción de los Estados caribeños a favor de la retención de aquella pena. La diferencia sigue pesando en las decisiones de esos Estados.

Por lo que toca a la América septentrional, no parece cercana la integración de los Estados Unidos de América como parte de la Convención Americana. Los requerimientos en este sentido no han tenido respuesta oficial favorable. La posición estadounidense frente a la Corte Penal Internacional, ${ }^{124} \mathrm{y}$ en general frente a determinados compromisos del orden internacional, permite suponer que aún se halla muy lejos la hora en que ese país se sume al tratado, con todas sus consecuencias, a pesar de que tuvo activa participación en la formulación de la CADH. Menos remota pudiera ser esa posibilidad en lo que respecta a Canadá, que mantiene una posición diferente ante las jurisdicciones internacionales. En importantes medios nacionales, oficiales inclusive, han surgido propuestas favorables a la incorporación de Canadá a la $\mathrm{CADH}$, con algunas reservas. ${ }^{125}$

Otra cuestión de suma importancia para ponderar el futuro de la protección internacional de los derechos humanos proyectada hacia América - y particularmente hacia Latinoamérica — es la recepción legislativa de la materia: constitucional y ordinaria, así como jurisprudencial. ${ }^{126}$ Se ha caminado hacia adelante en la reforma constitucional en los países de

123 Cfr. García Ramírez, Sergio, "Derecho a la vida y aplicación de la pena de muerte en la jurisprudencia de la Corte Interamericana de Derechos Humanos", Criminalia. Revista de la Academia Mexicana de Ciencias Penales, México, año LXVIII, núm. 2, mayo-agosto de 2002, pp. 59-76.

124 Cfr. García Ramírez, Sergio, La Corte Penal Internacional, México, Instituto Nacional de Ciencias Penales, 2002, pp. 290 y ss.

125 Cfr. Enhancing Canada's Role in the OAS. Canadian Adherence to the American Convention on Human Rights. Report of the Standing Senate Committee on Human Rights, The Senate, mayo de 2003, pp. 58 y ss.

126 Cfr. García-Sayán, Diego, "Una viva interacción: Corte interamericana y tribunales internos", en varios autores, La Corte Interamericana ..., cit., nota 1, pp. 323 y ss. El autor destaca cómo "importantes tribunales latinoamericanos vienen nutriéndose de la jurisprudencia de la Corte en un proceso que podríamos llamar de 'nacionalización del derecho internacional de los derechos humanos". Idem. 
América Latina, que establece el necesario enlace entre el sistema internacional y el sistema nacional ${ }^{127}$ y supera antiguos antagonismos y distancias inaceptables. Campea, cada vez más, la idea de que los órdenes interno e internacional convergen en una "decisión política fundamental", tanto doméstica como regional: prevalece la norma que más favorezca los derechos del ser humano, eje de ambos. ${ }^{128}$ En fin de cuentas, los órdenes nacional e internacional, conducidos por un criterio pro homine de amplio espectro, "deben necesariamente coexistir en la promoción, garantía y defensa de los derechos de la persona humana". ${ }^{129}$ Por su parte, la jurisdicción interamericana también acoge los pronunciamientos nacionales. ${ }^{130}$

127 Cfr. Villarroel Villarroel, Darío, Derecho de los tratados en las Constituciones de América, México, Porrúa, 2004, pp. 313 y ss.; así como Fix-Zamudio, Héctor y Valencia Carmona, Salvador, Derecho constitucional mexicano y comparado, 4a. ed., México, Porrúa, 2005, pp. 520 y ss. Igualmente, cfr. Quiroga Lavié, Humberto, "Estudio introductorio", El constitucionalismo en las postrimerías del siglo XX. Las Constituciones latinoamericanas, México, UNAM, Instituto de Investigaciones Jurídicas, 1994, t. I, pp. 24-26.

128 En diversa forma se ha manifestado esta colocación de los derechos humanos en la cúspide del orden normativo, cualquiera que sea su fuente. Los ejemplos abundan. Citemos dos. En Argentina, que a este respecto ofrece un ejemplo bien conocido y examinado, la reforma constitucional de 1994 elevó al rango de la Constitución los tratados de derechos humanos. Cfr. Vanossi, Jorge R., "Los tratados internacionales ante la reforma de 1994", en Abregú, Martín y Curtis, Christian (comps.), La aplicación de los tratados sobre derechos humanos por los tribunales locales, Buenos Aires, Centro de Estudios Legales y Sociales, 1997; Ayala Corao, Carlos, "La jerarquía de los tratados de derechos humanos", en Méndez y Cox (eds.), El futuro del Sistema Interamericano de Protección de los Derechos Humanos, San José, Instituto Interamericano de Derechos Humanos, 1998, pp. 137 y ss., y La jerarquía constitucional de los tratados relativos a derechos humanos y sus consecuencias, México, Querétaro, Colección Fundap, Derecho, Administración y Política, 2003. Con fórmula diversa, la Constitución de Venezuela sitúa los derechos humanos en aquella cúspide normativa: los tratados de derechos humanos "tienen jerarquía constitucional y prevalecen en el orden interno, en la medida en que contengan normas sobre su goce y ejercicio más favorables a las establecidas en esta Constitución y en las leyes de la República, y son de aplicación inmediata y directa por los tribunales y demás órganos del poder público" (artículo 23).

129 Gros Espiell, Héctor, "Universalismo y regionalismo en la protección internacional de los derechos humanos", en varios autores, Los tratados sobre derechos humanos y la legislación mexicana, México, UNAM, Instituto de Investigaciones Jurídicas, 1981, p. 8.

130 Acerca de esta mutua influencia, $c f r$. Fix-Zamudio, Héctor, "Justicia constitucional y derechos humanos en Latinoamérica", en López Guerra, Luis (coord.), La justicia constitucional en la actualidad, Quito, Tribunal Constitucional (de Ecuador)-Instituto de 
Me parece evidente el progreso de la tarea judicial internacional en este ámbito, a través de una doctrina jurisprudencial cada vez más abundante, incisiva y trascendente, que abarca ya una buena parte de la Convención Americana y de otros instrumentos internacionales sobre derechos humanos aplicables en Estados americanos. Estimo que el carácter progresista de esa jurisprudencia se ha mantenido e incrementado. El "puente" entre los órdenes nacional e internacional, "hemisferios" de una misma dedicación, se fortalece con la explícita recepción nacional, por parte de los tribunales internos, de la jurisprudencia interamericana que interpreta la $\mathrm{CADH}$ y otros instrumentos que poseen fuerza vinculante en el orden nacional. Son notables los desarrollos en esta dirección, que constituyen una de las novedades más estimables de los últimos años, ${ }^{131}$ cada vez mejor conocidas y documentadas. ${ }^{132}$

Los altos tribunales que se han pronunciado al respecto destacan la fuerza vinculante de la jurisprudencia de la Corte Interamericana, derivada de la incorporación de la $\mathrm{CADH}$ en el ordenamiento nacional y del carácter de aquélla como órgano convencional depositario de la facultad

Derecho Público Comparado, Facultad de Ciencias Sociales y Jurídicas, Universidad Carlos III (España)-Unión Europea-Corporación Editora Nacional, 2002, pp. 289-290.

131 Así lo destaqué en el informe presentado el 9 de marzo de 2006 a la Comisión de Asuntos Jurídicos y Políticos de la OEA ("La efectividad del Sistema Interamericano de Protección de los Derechos Humanos - como de otros sistemas universales o regionales - se mide por la forma en que trasciende al ámbito interno de los Estados. Esa trascendencia existe y crece"), y en el informe ante la Asamblea General de la misma Organización, el 6 de junio de 2006 ("Si tuviésemos que cifrar en un solo concepto los mayores logros de la jurisdicción interamericana en la etapa más reciente —que son, por supuesto, logros del Sistema en su conjunto-, habría que mencionar la recepción que la jurisprudencia internacional ha tenido en el orden jurídico interno de los Estados").

132 En 2006, la Corte Interamericana de Derechos Humanos, el Instituto Interamericano de Derechos Humanos, el Instituto de Investigaciones Jurídicas de la UNAM y la Fundación Konrad Adenauer iniciaron la publicación de la revista Diálogo Jurisprudencial. Derecho Internacional de los Derechos Humanos-Tribunales Nacionales-Corte Interamericana de Derechos Humanos (núm. 1, julio-diciembre de 2006), en la que se recogen sentencias nacionales de países americanos sustentadas en el derecho internacional de los derechos humanos y, más específicamente, en la jurisprudencia de la Corte Interamericana. El antecedente de esta publicación es la Revista Iudicium et Vita, publicada por el Instituto Interamericano de Derechos Humanos. Sobre la recepción de la jurisprudencia internacional en Argentina, $c f r$., por ejemplo, Hitters, Juan Carlos, "Los tribunales supranacionales", La Ley, Buenos Aires, año LXX, núm. 15, 16 de agosto de 2006. 
de interpretar y aplicar la Convención. ${ }^{133}$ La operación de ambos datos, conjuntamente, confiere a la jurisprudencia internacional la fuerza que comienza a tener en la corriente jurisprudencial latinoamericana.

Estimo igualmente necesario afianzar cada vez más la idea de que el Sistema Interamericano de Protección de los Derechos Humanos posee la estructura compleja a la que antes me referí, con las diversas consecuencias que entraña esa idea. Bajo este concepto, la función de los Estados es cada vez más relevante, tanto por el cumplimiento de sus propias decisiones políticas fundamentales internas, como por la observancia de las decisiones internacionales, a título de garantes del Sistema. Es necesario que éste, sujeto a revisión constante y profunda, opere con la participación convergente de quienes lo integran. La tutela internacional de los derechos debe operar "con" los Estados, no "contra" ellos.

Es deseable que se fortalezca la Corte Interamericana - y también, por supuesto, la Comisión Interamericana-, con la estructura y los recursos de diverso género que le permitan despachar sus atribuciones con la mayor eficacia. Desde luego, el Tribunal debe hacer su propia parte, como lo ha procurado a través de reformas reglamentarias y de nuevas prácticas que le permiten atender un mayor número de causas, sin detrimento de la calidad de sus pronunciamientos y de las garantías de los justiciables. Empero, es bien sabido que se requiere contar con una infraestructura que permita atender las crecientes necesidades de esta jurisdicción. Esto - como otras cosas- implica un gran esfuerzo de los Estados generadores y destinatarios del Sistema Interamericano.

133 Por ejemplo, la Corte Suprema de Argentina, en el Caso Giroldi, Horacio David y otros-recurso de casación, sentencia del 7 de abril de 1995, señaló que la jurisprudencia de la Corte es guía para interpretar los preceptos convencionales, en cuanto Argentina reconoció la competencia de aquélla en todos los casos de interpretación y aplicación de la Convención Americana. La misma Corte Suprema sostuvo, en el Caso Ekmekdian c. Sofovich, 1992, que "la interpretación del pacto debe... guiarse por la jurisprudencia de la Corte IDH, uno de cuyos objetivos es la interpretación de la Carta de San José". En el concepto de la Quinta Sala de la Corte de Apelaciones de Chile, la interpretación fidedigna y suprema de la CADH es la formulada por la Corte Interamericana. Casación en el Caso de desaparición de Miguel Ángel Sandoval Rodríguez por agentes de la DINA. Fallo del 15 de enero de 2004. En el fallo del 5 de enero de 2004 sobre el recurso de nulidad interpuesto por Lloyd Aéreo Boliviano, S. A., el Tribunal Constitucional de Bolivia afirmó que la jurisprudencia de la Corte IDH “es vinculante para la jurisdicción interna". 